\title{
CONSTRUÇÃO DE UM OBJETO DE DISCURSO E MEMÓRIA DISCURSIVA: O EXEMPLO DE CONSTANTINOPLA NOS RELATOS DE VIAGEM DO SÉCULO XVIII ${ }^{1}$
}

\author{
CONSTRUCTION D'UN OBJET DE DISCOURS ET MÉMOIRE \\ DISCURSIVE: L'EXEMPLE DE CONSTANTINOPLE DANS LES \\ RÉCITS DE VOYAGE AU XVIIIEME SIÈCLE
}

\author{
RACHELE RAUS ${ }^{2}$
}

Università degli Studi di Torino (UniTo, Italia)

Dipartimento di Culture, Politica e Società

Lungo Dora Siena 100/A, 10153 - Torino, Italia

rachele.rausdunito.it

\begin{abstract}
Resumo. A partir da minha tese de doutorado, tenho me debruçado sobre a análise de relatos de viagens, notadamente, os discursos que os viajantes franceses "teceram" em torno de turcos e turcas a partir do século XVI até primeira metade do século XIX. Voltarei a este assunto fazendo, agora, as seguintes perguntas: de que maneira a cidade de Constantinopla é descrita pelos viajantes no século XVIII quando prevalece o orientalismo de gabinete sobre o orientalismo de campo (AA.VV. 1998, p. 15)? Como um objeto se constrói em discurso?
\end{abstract}

Palavras-chave: relatos de viagens; descrição de Constantinopla; orientalismo; objeto de discurso.

Résumé. Depuis ma thèse de doctorat, je me suis penchée sur l'analyse des récits de voyage, notamment sur les discours que les voyageurs français ont " tissés » autour des Turcs et des Turques à partir du XVIème jusqu'à la première moitié du XIXème siècle. Je vais revenir maintenant sur ce sujet pour poser les questions suivantes: de quelle manière la ville de Constantinople est-elle décrite par les voyageurs au XVIIlème siècle, quand l'orientalisme de cabinet l'emporte sur l'orientalisme de terrain (AA.VV. 1998, p. 15) ? Comment un objet se construit-il en discours?

Mots-clés: récits de voyage; description de Constantinople; orientalisme; objet de discours.

\footnotetext{
${ }^{1}$ Versão em português de Débora Massmann.

2 Ph.D. pela Escola de Línguas Modernas para Intérpretes e Tradutores Universitários (SSLMIT) de Trieste. Diretora do Centro de Estudos sobre a Europa (TO-EU), do Departamento de Cultura, Política e Sociedade, da Universidade de Turim (Itália).
} 
A partir da minha tese de doutorado, tenho me debruçado sobre a análise de relatos de viagens, notadamente sobre os discursos que os viajantes franceses "teceram" em torno de turcos e turcas a partir do século XVI até primeira metade do século XIX. Voltarei a este assunto fazendo, agora, as seguintes perguntas: de que maneira a cidade de Constantinopla é descrita pelos viajantes no século XVIII quando prevalece $\mathrm{o}$ orientalismo de gabinete sobre o orientalismo de campo (AA.VV. 1998, p. 15)? Como um objeto se constrói em discurso? Para fazer isso, é necessário primeiro definir o sentido que se pode dar à expressão "objeto de discurso" (doravante, OdD), que retomamos de Lorenza Mondada (1994, p. 62), para o qual

\begin{abstract}
o "objeto de discurso" é um objeto constitutivamente discursivo, construído por meios e processos linguísticos [...] é no e pelo discurso que são postos, delimitados, desenvolvidos, transformados, objetos de discurso que não lhe pré-existem e que não têm uma estrutura fixa, mas que, pelo contrário, emergem e se elaboram progressivamente na dinâmica discursiva.
\end{abstract}

Esta definição nos convém quanto mais nos posicionamos como analistas de discurso, inscrevendo-nos na linha de Análise de Discurso (AD) que se desenvolveu na França seguindo o trabalho de Michel Pêcheux e Jean Dubois. São principalmente as nocões de interdiscurso, de pré-construído (HENRY, 1975) e de "memória discursiva", tal como será elaborada por Jean-Jacques Courtine (1981), Maingueneau (1984) e, mais recentemente, por Marie-Anne Paveau (2006, 2013), que utilizaremos neste trabalho.
Depuis ma thèse de doctorat, je me suis penchée sur l'analyse des récits de voyage, notamment sur les discours que les voyageurs français ont «tissés » autour des Turcs et des Turques à partir du XVIème jusqu'à la première moitié du XIXème siècle. Je vais maintenant revenir sur ce sujet en posant les questions suivantes : de quelle manière la ville de Constantinople est-elle décrite par les voyageurs au XVIIIème siècle quand l'orientalisme de cabinet l'emporte sur l'orientalisme de terrain (AA.VV. 1998, p. 15) ? Comment un objet se construit-il en discours ? Pour ce faire, il faut d'abord préciser le sens qu'on peut donner à l'expression « objet de discours » (désormais OdD) et que nous reprenons à Lorenza Mondada (1994, p. 62), pour laquelle

\begin{abstract}
l'« objet de discours» est un objet constitutivement discursif, construit par des moyens et des processus linguistiques [...] c'est dans et par le discours que sont posés, délimités, développés, transformés, des objets de discours qui ne lui préexistent pas et qui n'ont pas une structure fixe, mais qui au contraire émergent et s'élaborent progressivement dans la dynamique discursive.
\end{abstract}

Cette définition nous convient d'autant plus que nous nous positionnons en analyste du discours, en nous inscrivant dans la lignée de l'analyse du discours (AD) telle qu'elle s'est développée en France suite aux travaux de Michel Pêcheux et de Jean Dubois. Ce sont notamment les notions d'interdiscours, de préconstruit (HENRY, 1975) et de "mémoire discursive », telle qu'elle sera élaborée par Jean-Jacques Courtine (1981), Maingueneau (1984) et plus récemment par Marie-Anne Paveau (2006, 2013), que nous allons utiliser dans ce travail. 


\section{O DISCURSO DE VIAGEM NO SECULO XVIII}

Vários pesquisadores concordam que, no século XVIII, assiste-se a uma desaceleração de viagens francesas no Levante Otomano motivada por diferentes fatores. Francesco Fiorentino (1982, p. 73) encontra o motivo disso na presença de uma metarreflexão nos textos de viagem e, consequentemente, num fervor intelectual que teria enfraquecido o interesse a partir do século XVIII, o que, acrescentamos, teria terminado por favorecer o orientalismo de gabinete; de acordo com Pierre Martino (1906), os interesses dos viajantes do século XVIII estariam direcionados à China e ao Extremo Oriente. Como já havíamos insistido anteriormente (RAUS, 2003a) há, de um lado, as mudanças de interesses diplomáticos da França e, de outro lado, o clima político que se instaurou na França durante a segunda metade do século XVIII.

No que diz respeito ao primeiro assunto, de fato, o historiador Ernest Charrière (1848, III) destaca o abandono, operado pela França, de uma política de aliança com o Império Otomano, uma aliança que, diz ele, tinha desempenhado um papel essencial a partir do século XVI para "formar uma manobra poderosa contra a casa da Áustria". Em relação ao clima político, os anos próximos à Revolução Francesa são caracterizados por longos atrasos na publicação de relatos, como descreve o viajante Choiseul-Gouffier (1842, vol. 2, p. 2-3), cuja narrativa só será publicada no século seguinte:

neste tempo de delírio, onde a própria indigência foi despojada como riqueza, onde se persegue o gênio sem perdoar a mediocridade, os materiais que eu tinha conseguido recolher [no que diz respeito

\section{Le discours de voyage au XVIIIème siècle}

Plusieurs chercheurs s'accordent à dire qu'au XVIIIème siècle on assiste à un ralentissement des voyages français dans le Levant Ottoman, ce qui a été motivé de plusieurs manières. Francesco Fiorentino (1982, p. 73) en trouve la raison dans la présence d'une métaréflexion sur les textes de voyage et, par conséquent, dans une ferveur intellectuelle qui aurait produit l'affaiblissement de l'intérêt à partir au XVIIIème siècle, ce qui, ajoutons-nous, aurait finit par favoriser l'orientalisme de cabinet ; selon Pierre Martino (1906), les intérêts des voyageurs du XVIIIème siècle se seraient orientés vers la Chine et l'Extrême Orient. Nous avons plutôt insisté (RAUS, 2003a) d'une part, sur les changements d'intérêts diplomatiques de la France et de l'autre, sur le climat politique qui s'instaure en France pendant la seconde moitié du XVIIIème siècle.

À l'égard du premier sujet, en effet, l'historien Ernest Charrière (1848, III) souligne l'abandon, opéré par la France, d'une politique d'alliance avec l'empire ottoman, alliance qui, nous ditil, avait joué un rôle essentiel depuis le XVIe siècle pour " former une diversion puissante contre la maison d'Autriche ». Par rapport au climat politique, les années aux alentours de la Révolution française se caractérisent par de forts retards dans la publication de récits, comme le précise le voyageur ChoiseulGouffier (1842, vol. II, p. 2-3), dont le récit ne sera publié qu'au siècle suivant :

dans ce temps de délire, où l'indigence elle-même fut dépouillée comme la richesse, où l'on persécuta le génie sans faire grâce à la médiocrité, les matériaux que j'avais pu recueillir [pour ce qui est de 
a sua viagem para Oriente] foram espalhados e quase aniquilados ${ }^{\mathrm{i}}$.

Entretanto, a ausência de relatos parece ser compensada pela produção de textos literários sobre a Turquia otomana, entre outros, " anedotas » que se tornam um verdadeiro gênero de discruso.

Em relação aos "discursos de viagem", é preciso destacar que é justamente no século XVIII que eles se tornam um tipo de discurso autônomo, que se realiza sob gêneros discursivos precisos: o relato de viagem e a viagem pitoresca. Se o primeiro, que pode ser realizado na forma de relações, letras ou mais raramente diário íntimo, segue a tradição inaugurada no século anterior, a viagem pitoresca é um gênero introduzido justamente no século XVIII para designar o início do processo de escrita de um texto a partir de imagens produzidas por pintores enviados para o Levante ii . Esta aproximação entre pintura e escrita já é anunciada nos relatos de viagem antes mesmo de se materializar em um gênero discursivo a parte. Eis aqui o que o primeiro viajante do século XVIII, que consideramos em nosso corpus, Pitton de Tournefort, nos fala sobre esse assunto: "é muito triste também ver coisas bonitas sem poder desenhá-las [...] Por uma felicidade singular, encontrei um pintor inteligente, o Sr. Gundescheimer".

Observemos também que, sempre nos relatos de viagem do século XVIII, encontra-se o traço discursivo da paralelização da escrita com a pintura pela presença do verbo "pintar" no interior das relações. son voyage en Orient] furent dispersés et presque anéantisi.

Cependant, le manque de récits semble être compensé par la production de textes littéraires sur la Turquie ottomane, entre autres, des « anecdotes » qui deviennent un véritable genre de discours.

Par rapport au «discours de voyage $»$, il faut remarquer que c'est justement pendant le XVIIIème siècle qu'il devient un véritable type de discours autonome, qui se réalise sous des genres de discours précis : le récit de voyage et le voyage pittoresque. Si le premier, qui peut se réaliser sous forme de relations, de lettres ou plus rarement de journal intime, poursuit la tradition inaugurée au siècle précédent, le voyage pittoresque est un genre introduit justement au XVIIIème siècle pour désigner, au tout début, le processus d'écriture d'un texte à partir des images produites par des peintres envoyés au Levant $^{\text {ii }}$. Ce rapprochement entre peinture et écriture est déjà annoncé dans les récits de voyage avant même de se concrétiser dans un genre discursif à part. Voici ce que le premier des voyageurs du XVIIIème siècle que nous avons considérés dans notre corpus, Pitton de Tournefort, nous dit à ce sujet : " Il est fort chagrinant aussi de voir de belles choses sans les pouvoir faire dessiner [...] Par un bonheur singulier je trouvai un habile peintre, M. Gundescheimer ».

Précisons également que, toujours dans les récits de voyage du XVIIIème siècle, on trouve la trace discursive de la mise en parallèle de l'écriture avec la peinture par la présence du verbe «peintre» à l'intérieur des relations. 
Para além dos gêneros discursivos, o discurso de viagem é atualmente compreendido como um tipo de discurso autônomo e legítimo, já que dispõe de uma tradição específica ${ }^{\text {iii }}$. A este respeito, é útil lembrar o papel do interdiscurso no âmbito da elaboração de tipos e gêneros de discurso, especialmente, da memória discursiva. É precisamente em relação a este assunto que Maingueneau destaca a presença constitutiva de duas memórias, uma interna aos textos e a outra externa (MAINGUENEAU, 1984, p. 131): "O discurso é um requerente de tradição e criador de sua própria tradição [...] Dupla memória que é polêmica".

Essa dupla memória polêmica está efetivamente presente desde os relatos do século XVI. A presença de uma configuração discursiva ${ }^{\mathrm{iv}}$ sobre $\mathrm{o}$ topos de Ulysses (RAUS, 2001a) testemunha justamente a presença de uma memória discursiva exterior que valida o dito em questão. Este autêntico lugar comum, que abre os relatos de viagens do século XVI, pode ser esquematizado da seguinte forma:

[a] Para ter observado $\mathrm{Y}$ propõe $\mathrm{Z}$ sábio $+\mathrm{X}+\quad+$ a diversidade

[b] Para ter conhecido

Onde: $\mathrm{Y}=$ "o poeta grego / Homero / ø [a palavra fica implícita na construção impessoal] $\mathrm{Z}=$ Ulysses $\mathrm{X}=$ eloquente / acordo/ø.

O que nos interessa é ver que é, justamente, o apoio em um autor grego que permite ao discurso de viagem se legitimar durante o século XVI. Entretanto, o interdiscurso que caracteriza o século XVII facilita a circulação e a recuperação do dito dos
Par delà les genres discursifs, le discours de voyage est désormais ressenti comme un type de discours autonome et légitime, puisque disposant désormais d'une tradition propre ${ }^{\mathrm{iii}}$. À ce sujet, il est utile de rappeler le rôle de l'interdiscours au niveau de l'élaboration des types et des genres de discours, notamment de la mémoire discursive. C'est justement à ce sujet que Maingueneau souligne la présence constitutive de deux mémoires, l'une intérieure aux textes et l'autre extérieure (MAINGUENEAU, 1984, p. 131): «le discours est demandeur de tradition et créateur de sa propre tradition [...] Double mémoire qui est polémique».

Cette double mémoire polémique est en effet présente dès les récits du XVIème siècle. La présence d'une configuration discursive $^{\text {iv }}$ concernant le topos d'Ulysse (RAUS, 2001a) témoigne justement de la présence d'une mémoire discursive extérieure qui valide le dit en question. Ce véritable lieu commun, qui ouvre les récits de voyage du XVIème siècle, on peut le schématiser de la manière suivante :

[a] Pour avoir observé $\mathrm{Y}$ propose $\mathrm{Z}$ sage $+\mathrm{X}+\quad+$ la diversité

[b] Pour avoir connu

Où: $\mathrm{Y}=$ "le poète grec / Homère / ø [le mot reste implicite dans la construction impersonnelle] $\mathrm{Z}=$ Ulysse $\mathrm{X}=$ éloquent / accort /ø.

Ce qui nous intéresse est de voir que c'est l'appui sur un auteur grec qui permet au discours de voyage de se légitimer au cours du XVIème siècle. Par contre, l'interdiscours caractérisant le XVIIème siècle facilite la circulation et la reprise du dit des voyageurs 
viajantes anteriores e viabiliza a criação de uma memória interna ao discurso que tornar-se-á autonomia no século XVIII e, assim, preencherá, em decorrência, qualquer necessidade de legitimação pela diafasia a partir de um discurso-outro. $\mathrm{O}$ traço enunciativo da recente tradição do discurso de viagem no interior dos relatos sobre o Levante otomano é precisamente a presença do interdiscurso que se apoia desta vez nos viajantes anteriores: por exemplo, Pitton de Tournefort cita Pierre Belon, Jean de Thevenot, Jean Chardin, Jean-Baptiste Tavernier, Jacob Spon e outros viajantes, Paul Lucas cita frequentemente Spon e Barthelemy D'Herbelot... Não somente isso, mas também a presença de configurações de enunciados em torno do paradigma "todo mundo sabe/sabe$\mathrm{se}^{\prime}$ atua como garantia que legitima o dito, um princípio de autoridade doxal, que garante a veracidade do dito e o legitima pelo implícito de um "terceiro falante" (PEYTARD apud PAVEAU, 2015) representado pelo testemunho dos viajantes (sabe-se porque os viajantes o disseram). Além disso, o recurso a nãopessoa "todo mundo/se v" cria uma espécie de comunhão, de partilha entre o enunciador e o co-enunciador que está inscrita no discurso.

Aqui estão alguns exemplos do processo de produção de sentido pelo "sabe-se/todo mundo conhece" em Paul Lucas (1719) ${ }^{\text {vi: }}$

(T.I-89) Sabe-se que os turcos não usam sinos ou relógios públicos.

(T.I-30) Sabe-se que esta é a maneira de viajar na Turquia: e não devemos esperar encontrar tais hospedarias tão comuns nas grandes estradas da França e nos países vizinhos.

(T.II-p.117) É inútil dizer de que modo as mulheres são cuidadas [...], todo mundo conhece o ciúme dos orientais (T.II-123) Sabe-se que não é permitido aos seguidores de Maomé ter mais de quatro mulheres legítimas e que o précédents et permet la création d'une mémoire interne au discours, qui deviendra autonome au XVIIIème siècle et s'acquittera, par conséquent, de toute nécessité de légitimation par la diaphasie à partir d'un discours-autre. La trace énonciative de la naissante tradition du discours de voyage à l'intérieur des récits concernant le Levant ottoman est justement la présence de l'interdiscours qui s'appuie cette fois-ci sur les voyageurs précédents: par exemple, Pitton de Tournefort cite Pierre Belon, Jean de Thévenot, Jean Chardin, JeanBaptiste Tavernier, Jacob Spon et d'autres voyageurs, Paul Lucas cite souvent Spon et Barthélemy D'Herbelot... Non seulement, mais la présence de configurations d'énoncés autour du paradigme « tout le monde sait / on sait », joue comme garant qui légitime le dit, un principe d'autorité doxique, qui garantit la véridicité du dit et le légitime par l'implicite d'un « tiersparlant» (PEYTARD dans PAVEAU, 2015) représenté par le témoignage des voyageurs (on sait parce que les voyageurs l'ont dit). En outre, le recourt à la non-personne « tout le monde / on » crée une sorte de communion, de partage entre l'énonciateur et le co-énonciateur qui est inscrit en discours.

Voici quelques exemples de l'institution du sens par le « on sait / tout le monde connaît » dans Paul Lucas $(1719)^{\mathrm{vi}}$ :

(T.I- 89) On sçait que les Turcs ne se servent point de cloches ni d'horloges publiques.

(T.I- 30) On sçait que c'est la maniere de voyager en Turquie: \& il ne faut pas s'attendre à trouver de ces Hôtelleries si communes sur les grands chemins en France \& dans les Païs voisins.

(T.II- pg 117) Il est inutile de dire de quelle sorte les femmes sont gardées [...], tout le monde connoît là-dessus la jaloufie des Orientaux. 
número de suas concubinas é limitado apenas pelas suas capacidades.

A presença desta memória é o que justifica o bloqueio do sentido vii . O objeto de discurso Constantinopla está agora saturado pelo interdiscurso de viajantes anteriores. É justamente por esta razão que, no início do século XVIII, Paul Lucas, fazendo o elogio do discurso dos viajantes anteriores, especificará (1704, vol. 2, 291): “não é necessário me extinguir sobre o que há de particular em Constantinopla, a quantidade de relações que se tem dela me poupa esforços".

Alguns anos depois, o Conde de Caylus lhe fará eco, afirmando sobre o mesmo assunto que (1802, p. 404): "Constantinopla é tão bem descrita e tão conhecida na Europa que não vou me comprometer a pintar uma imagem dela; mas informarei o que vi e a impressão que tive".

Retornaremos mais adiante, justamente, sobre a novidade das coisas curiosas que esses viajantes se limitam a acrescentar em seus relatos, seu dito estando assim enquadrado pelo interdiscurso dos viajantes anteriores.

\subsection{A CONSTRUÇÃO DE OdD}

\subsubsection{CONSTRUÇÃO DE OdD E INTERDISCURSO}

Mas como essa memória discursiva, essa tradição de discurso de viagem constrói o OdD? Para vê-lo, daremos o exemplo da descrição de um dos locais típicos descritos pelos viajantes: o caravançarai viii, edifício pitoresco do Levante otomano que
(T.II-123) On sçait qu'on n'est pas permis aux sectateurs de Mahomet d'avoir plus de quatre femmes légitimes, \& que le nombre de leurs concubines n'est borné que par leurs facultés.

La présence de cette mémoire est ce qui justifie le blocage du sens. L'objet de discours Constantinople est désormais saturé par l'interdiscours des voyageurs précédents. C'est justement pour cela qu'au début du XVIIIème siècle, Paul Lucas, en faisant l'éloge du discours des voyageurs précédents, précisera (1704, vol. 2, 291) : «Il n'est pas nécessaire de m'éteindre sur ce qu'il y a de particulier dans Constantinople, la quantité de relations qu'on en a m'en épargne la peine. »

Quelques ans après, le Comte de Caylus lui fera écho, en précisant au même sujet que (1802, p. 404) : «Constantinople est si bien décrite et si connu en Europe que je n'en entreprendrai point d'en faire le tableau ; mais je rapporterai ce que j'ai vu, et l'impression que j'en ai reçue. »

Nous reviendrons justement sur la nouveauté des choses curieuses que ces voyageurs se limitent à ajouter par leurs récits, leur dit étant donc encadré par l'interdiscours des voyageurs précédents.

\subsection{La construction de l'OdD}

\subsubsection{Construction de l'OdD et interdiscours}

Mais comment cette mémoire discursive, cette tradition du discours de voyage construit-elle l'OdD ? Pour le voir, donnons l'exemple de la description de l'un des lieux typiques décrits par les voyageurs : le caravansérail, bâtiment pittoresque du Levant ottoman qui 
permite traçar a presença de configurações de enunciados interessantes. Eis aqui como aparecem os enunciados sobre o caravançarai no século XVI:

\begin{tabular}{|l|l|}
\hline \multicolumn{1}{|c|}{ AUTOR } & \multicolumn{1}{|c|}{ ENUNCIADO } \\
\hline Belon & $\begin{array}{l}\text { 1a- querendo dar a entender } \\
\text { que não há hospedaria na } \\
\text { Turquia, falaremos de um } \\
\text { grande edifício [...] que os } \\
\text { turcos de nome próprio } \\
\text { chamam de Carbacharaix }\end{array}$ \\
\hline Postel & $\begin{array}{l}\text { 1b- na Turquia não há } \\
\text { nenhuma hospedaria ou } \\
\text { Taverna. há nenhuma }\end{array}$ \\
\hline Villamont & $\begin{array}{l}\text { 1c- não há nas nas } \\
\text { hospedaria na Turquia, mas } \\
\text { muitas Carbacharas nas } \\
\text { estradas [...]. }\end{array}$ \\
\hline
\end{tabular}

O paradigma retratado insiste sobre a ausência de hospedarias na Turquia. Este mesmo paradigma evolui no século seguinte, como mostram os enunciados retirados dos viajantes no século XVII:

\begin{tabular}{|l|l|}
\hline \multicolumn{1}{|c|}{ AUTOR } & \multicolumn{1}{c|}{ ENUNCIADO } \\
\hline Du Loir & $\begin{array}{l}\text { 2a- não há definitivamente } \\
\text { outras hospedarias em todo } \\
\text { Levante [com exceção das } \\
\text { Kiarvanserais]. }\end{array}$ \\
\hline Poulet & $\begin{array}{l}\text { 2b- não há definitivamente } \\
\text { outras hospedarias em todo } \\
\text { Levante [com exceção das } \\
\text { Kiarvanserais]. }\end{array}$ \\
\hline Quiclet & $\begin{array}{l}\text { 2c- não há outras hospedarias } \\
\text { apenas Kiarvanserais. }\end{array}$ \\
\hline
\end{tabular}

Duas mudanças devem ser observadas no paradigma do século XVII: por um lado, a negação absoluta ("não há definitivamente / não / nenhuma hospedaria(s)") se transforma em uma negação restritiva ("não há outra hospedaria ... apenas"), e, por outro lado, a reformulação de "Turquia" para "Levante". permet de retracer la présence de configurations d'énoncés intéressantes. Voici comment se présentent les énoncés concernant le caravansérail au XVIème siècle :

\begin{tabular}{|l|l|}
\hline \multicolumn{1}{|c|}{ AUTORE } & \multicolumn{1}{|c|}{ ENUNCIATO } \\
\hline Belon & $\begin{array}{l}\text { 1a- volant donner à entendre } \\
\text { qu'il n'y a point d'hostellerie en } \\
\text { Turquie, parlerons d'un grand } \\
\text { edifice [...] que les Turcs de } \\
\text { nom propre appellent un } \\
\text { Carbachara. }\end{array}$ \\
\hline Postel & $\begin{array}{l}\text { 1b- en Turquie il n'y a nulles } \\
\text { hostelleries ou Tauerne. }\end{array}$ \\
\hline Villamont & $\begin{array}{l}\text { 1c- il n'y a aucune hostellerie } \\
\text { en Turquie, mais bien des } \\
\text { Carbacharas sur les grands } \\
\text { chemins [...]. }\end{array}$ \\
\hline
\end{tabular}

Le paradigme retracé insiste sur l'absence d'hôtelleries en Turquie. Ce même paradigme évolue au siècle suivant, comme le montrent les énoncés tirés des voyageurs du XVIIème siècle :

\begin{tabular}{|c|c|}
\hline AUTORE & ENUNCIATO \\
\hline Du Loir & $\begin{array}{l}\text { 2a- il n'y a point d'autres } \\
\text { hostelleries dans tout le Levant } \\
\text { [à l'excéption } \\
\text { Kiarvanserais]. }\end{array}$ \\
\hline Poulet & $\begin{array}{l}\text { 2b- il n'y a point d'autres } \\
\text { hostelleries dans tout le Levant } \\
\text { [à l'excéption } \\
\text { Kiarvanserais]. }\end{array}$ \\
\hline Quiclet & $\begin{array}{lrr}\text { 2c- il n'y a point } & \text { d'autres } \\
\text { hostelleries } & \text { que } & \text { le } \\
\text { Kiarvanserais. } & & \\
\end{array}$ \\
\hline
\end{tabular}

Deux changements sont à remarquer dans le paradigme $d u$ XVIIème siècle : d'une part, la négation absolue (« il n'y a point / nulles / aucune hostellerie(s) ») se transforme en négation restrictive («il n'y a point d'autres hostelleries... que $»)$, et de l'autre, la reformulation de "Turquie» par « Levant ». 
A primeira mudança, que não se deve à recategorização do real, este último evoluindo muito pouco até o século XIX, se explica considerando que a "hotelaria" é um referente europeu. A negação absoluta implica, portanto, a ausência de lugares europeus na Turquia e a presença de lugares que não têm nada a ver com o referente ocidental, tal como o caravançarai. O referente turco é então considerado como alteridade à parte, o que não acontece mais a partir do século seguinte, quando os viajantes falam da presença de uma única hospedaria do Levante: o caravançarai. Dessa maneira, eles reduzem a distância do outro, tornando-o diferente em relação a eles. Em comparação, o Levante é julgado pela falta de características ocidentais, o que, no século XVIII, modalizará o dito pela axiologia negativa:

(Spon) Os turcos não têm a ideia de estabelecer como nós boas hospedarias. (Tavernier) Os caravançarais são as hospedarias dos Levantinos [...] elas não são tão confortáveis para os ricos quanto as nossas pousadas na Europa.

Em relação à reformulação de Turquia por Levante, trata-se da prova subsequente do que havíamos demonstrado anteriormente (RAUS, 2003b, p. 45-46), a saber, o fato de o Turco se tornar o protótipo do muçulmano a partir do século XVII e, por consequência, o representante por excelência deste espaço geográfico impreciso que é o Levante.

Dito isto, o exemplo do caravançarai demonstra:

1. que a percepção dos lugares e suas descrições estão ligadas, por um lado, ao pré-construído que tende a bloquear o sentido e aos sujeitosenunciadores em um já-lá
Le premier changement, qui n'est pas dû à la recatégorisation du réel, ce dernier n'évoluant que très peu jusqu'au XIXème siècle, s'explique en considérant que l' «hôtellerie » est un référent européen. La négation absolue implique donc l'absence de lieux européens en Turquie et la présence de lieux qui n'ont rien à voir avec le référent occidental, tel le caravansérail. Le référent turc est alors considéré comme altérité à part, ce qui n'arrive plus à partir $\mathrm{du}$ siècle suivant, quand les voyageurs parlent de la présence d'une seule hôtellerie levantine : le caravansérail. De cette manière, ils réduisent la distance de l'autre, en le rendant différent par rapport à eux. Lors de la comparaison, le Levant est jugé par le manque des traits occidentaux, ce qui, au XVIIIème siècle, modalisera le dit par l'axiologie négative :

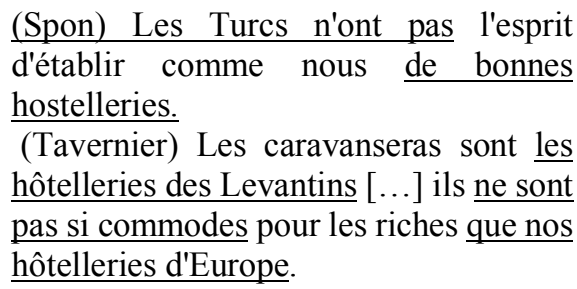

Par rapport à la reformulation de la Turquie par le Levant, il s'agit de la preuve ultérieure de ce que nous avons démontré ailleurs (RAUS, 2003b, p. 4546), à savoir le fait que le Turc devient le prototype du musulman à partir du XVIIème siècle et, par conséquent, le représentant par excellence de cet espace géographique flou qu'est le Levant.

Cela dit, l'exemple du caravansérail démontre :

1. que la perception des lieux et leurs descriptions sont liées d'une part, aux préconstruit qui tend à bloquer le sens et les sujets-énonciateurs dans un déjà-là naturalisé par la 
naturalizado pela reiteração e, por outro lado, à evolução da hiperlíngua (Auroux, 1997) que movimenta o interdiscurso e inaugura memórias parcialmente novas (da descrição "científica" de um referente em si à descrição de um referente que é julgado em relação a si mesmo ${ }^{\mathrm{x}}$ );

2. que a presença de uma tradição do discurso de viagem ("sabe-se") no século XVIII apenas contribui para a naturalização de um discurso que se destaca cada vez mais da descrição científica.

No que se refere à evolução das descrições, salientemos que o duplo status, científico e literário do relato de viagem, tal como foi justamente destacado por vários pesquisadores (FIORENTINO, 1982; BERTI, 1995...), faz com que esses dois pólos possam surgir diferentemente ao longo dos séculos privilegiando mais uma "cientificidade imperfeita" ou ainda uma "literalidade imperfeita" (FIORENTINO, 1982, p. 10).

\subsubsection{CONSTRUÇÃO DE OdD CONSTANTINOPLA: O EXEMPLO DO HAREM}

A descrição de Constantinopla no século XVIII deve ser enquadrada no interior de um interdiscurso que se caracteriza não apenas pela saturação da memória e pelo bloqueio do sentido, como mostram os fragmentos de Lucas e Caylus que havíamos citado, mas também pela tendência de privilegiar uma descrição axiologizada de lugaresoutros que são reconduzidos ao Ocidente. Observemos que os locais descritos, principalmente os elementos do pitoresco da cidade, como o palácio, o besestain (mercado), as mesquitas, os cafés, etc. que, a partir do século XVI, são normalmente descritos de acordo com a linearidade do percurso réitération, et de l'autre, à l'évolution de l'hyperlangue (Auroux 1997) qui bascule l'interdiscours et inaugure des mémoires partiellement nouvelles (de la description « scientifique » d'un référent en soi à la description d'un référent qui est jugé par rapport à $\operatorname{soi}^{\mathrm{x}}$ ) ;

2. que la présence d'une tradition du discours de voyage (« on sait») au XVIIIème siècle ne fait que contribuer à la naturalisation d'un discours qui se détache de plus en plus de la description scientifique.

Pour ce qui est de l'évolution des descriptions, signalons que le double statut, scientifique et littéraire du récit de voyage, tel qu'il a été justement souligné par plusieurs chercheurs (FIORENTINO, 1982; BERTI, 1995...), fait que ces deux pôles puissent émerger différemment le long des siècles, en privilégiant plutôt une «scientificité imparfaite» ou bien une "littérarité imparfaite » (FIORENTINO, 1982, p. 10).

\subsubsection{Construction de l'OdD Constantinople : l'exemple du sérail}

La description de Constantinople au XVIIIème siècle est donc à encadrer à l'intérieur d'un interdiscours qui se caractérise non seulement par la saturation de la mémoire et par le blocage du sens, comme le montrent les extraits de Lucas et de Caylus que nous avons cités, mais aussi par la tendance à privilégier une description axiologisée des lieux-autres qui sont reconduits à l'Occident. Remarquons que les lieux décrits, notamment les éléments du pittoresque de la ville comme le sérail, le besestain (marché), les mosquées, les cafés, etc. qui, depuis le XVIème siècle, sont normalement décrits d'après la linéarité $d u$ parcours (MONDADA, 
(MONDADA, 2000, p. 217) ${ }^{\mathrm{xi}}$, são agora apresentados em relação às pessoas, como veremos, fornecendo o exemplo do palácio.

A segunda coisa que caracteriza o interdiscurso sobre Constantinopla é a presença de mecanismos de prototipia e de estereotipia próximos daqueles descritos por Paul Siblot para a palavra "casbah" (1997). Por exemplo, o harém, que em turco geralmente designa o palácio de um homem rico, na literatura de viagem remete por prototipia ao palácio do sultão. Ainda que este último tivesse vários no Império Otomano, o harém descrito pelo viajante é o de Constantinopla ${ }^{\mathrm{xii}}$.

Vejamos agora a descrição desse harém, que, como diz o Conde de Caylus, é "o lugar que os europeus mais ocuparam". Trata-se, de fato, do lugar simbólico do Oriente muçulmano ao ponto que, durante a perda do pitoresco turco no século XIX devido às mudanças históricas ocorridas, Henry Cornille irá defini-lo como "o enigma da Turquia, o mistério do Oriente" (1833, p. 54).

Este lugar simbólico é descrito, de um lado, como um lugar fechado (I), e, por outro lado, como o lugar onde o Sultão (II) está confinado, como se pode observar nestes enunciados dos séculos XVII e XVIII:

I

(Stochove) grande Serralho fechado por altos muralhas.

(Baudier) a Casa Imperial, que é o Serralho [... as portas são cuidadosamente guardadas.

(Galland) no recinto do Serralho de Constantinopla.

(Tavernier) O grande Serralho é um vasto recinto [...] as paredes e as torres que compõem o recinto do Serralho parecem uma prisão espantosa.
2000 , p. 217$)^{\mathrm{xi}}$, sont maintenant décrits par rapport aux personnes, comme nous verrons en donnant l'exemple du sérail.

$\begin{array}{ccc}\text { La deuxième chose } & \text { qui } \\ \text { caractérise } & \text { l'interdiscours } & \text { sur }\end{array}$ Constantinople est la présence de mécanismes de prototypie et de stéréotypie proches de ceux que Paul Siblot a décrits pour le mot « casbah » (1997). Par exemple, le sérail, qui en Turquie désigne généralement le palais d'un riche, dans la littérature de voyage renvoie par prototypie au sérail du sultan. Bien que ce dernier en eût plusieurs dans l'Empire ottoman, le sérail décrit par le voyageur est celui de Constantinoplexii.

Venons donc à la description de ce sérail, qui, comme le précise le Comte de Caylus, est «le lieu dont les Européens se sont le plus occupés ». Il s'agit, en effet, du lieu symbole de l'Orient musulman, au point que lors de la perte du pittoresque turc au XIXème siècle à cause des changements historiques survenus, Henry Cornille le définira «l'énigme de la Turquie, le mystère de l'Orient » (1833, p. 54).

Ce lieu symbole est décrit d'une part, comme lieu fermé, enclos (I), et de l'autre, comme le lieu de l'enfermement du sultan (II), comme on peut le voir par ces énoncés du XVIIème et XVIIIème siècle :

I

(Stochove) grand Serrail enfermé de hautes murailles.

(Baudier) la Maison Imperiale, qui est le Serrail [...] les portes soient soigneusement gardées.

(Galland) dans l'enclos du Serrail de Constantinople.

(Tavernier) Le grand Serrail est un vaste enclos $[\ldots]$ les murs \& les tours qui font l'enclos du Serrail ressemblent à une affreuse prison. 
II

(Stochove) O Serralho do Grande Senhor é como uma república à parte. (La Boullaye-le-Gouz) O Grande Senhor, o povo só o vê quando ele sai de seu Serralho.

(Baudier) Os monarcas Otomanos, como Príncipes retirados em seus Serralhos $[\ldots]$.

O confinamento não caracteriza apenas o sultão, mas também as mulheres que vivem dentro do serralho, no harémlik ou no harém, como mostram os enunciados dos séculos XVII e XVIII:

\section{[1500]}

[Nicolay] casas onde elas [as turcas] estão continuamente presas pelo grande ciúme de seus maridos.

[Palerna] a casa, onde elas [as turcas] geralmente estão fechadas, seja pelo ciúme dos maridos seja pelo costume dos anciãos.

\section{[1600]}

[Thevenot], os franceses dizem Serralho tomando este conjunto apenas pelo apartamento em que estão fechadas as mulheres.

[Quiclet] O segundo apartamento é aquele das mulheres que lá estão fechadas.

Este paradigma evoluirá no
século XVIII em função do
acontecimento semântico que
descrevemos em outra publicação
(RAUS, 2003b) e que vincula o
confinamento das mulheres no harém
não ao ciúme dos maridos, mas à falta de
liberdade típica de um governo tirano, tal
como aquele do sultão, conforme
apontam esses enunciados de Tournefort
e Lucas:

[1700]

[Tournefort] a maioria das mulheres turcas é obrigada a ficar em casa.

[Lucas] A Lei e a Política as [as mulheres] mantêm trancadas no fundo dos Serralhos.

\section{II}

(Stochove) Le Serrail du Grand Seigneur est comme une republique à part.

(La Boullaye-le-Gouz) le Grand Seigneur, le peuple ne le voit que lors qu'il sort de son Serrail.

(Baudier) Les Monarques Ottomans, comme Princes retirez dans leurs Serrails [...].

L'enfermement ne caractérise pas seulement le sultan mais aussi les femmes qui vivent à son intérieur, dans le haremlik ou harem, comme le montrent les énoncés du XVIIème et du XVIIIème siècles :

\section{[1500]}

[Nicolay] maisons où elles [les Turques] sont continuellement enfermées pour la grande jalousie de leurs maris.

[Palerne] la maison, où elles [les Turques] sont ordinairement renfermées, soit pour la ialouzie des maris, que par coustume des anciens.

\section{[1600]}

[Thévenot] les François disent Serrail le prenans, ce semble, seulement pour l'appartement où sont serrées les femmes.

[Quiclet] Le second appartement est celuy des femmes qui y sont enfermez.

Ce paradigme évoluera au XVIIIème siècle en raison de l'événement sémantique que nous avons décrit ailleurs (RAUS, 2003b) et qui relie l'enfermement des femmes dans le harem non pas avec la jalousie des maris, mais avec l'absence de liberté typique d'un gouvernement tyrannique, tel celui du sultan, comme le montrent ces énoncés de Tournefort et de Lucas :

\section{[1700]}

[Tournefort] la plûpart des femmes turques sont obligez de rester chez elles. [Lucas] La Loi \& la politique les [les femmes] tiennent enfermées dans le fond des Serrails. 
Esta evolução discursiva já caracterizava o confinamento do Sultão, que nos discursos do século XVII era representado como um ídolo venerado por seus sujeitos, isolado como um Deus (RAUS, 2003a), enquanto que no século XVIII, o Serralho se torna mais (TOTT) "o asilo impenetrável (... do $)$ despotismo", lugar onde um déspota que subjuga seu povo se fecha.

Se a construção discursiva do serralho no século XVIII continua a ser, pois, a mesma em relação ao confinamento, o ponto de vista dos sujeitos-enunciadores varia muito. Assim como ocorre para o caravançarai, o serralho e, em seu interior, o apartamento das mulheres são construídos em relação à denúncia dos governos despóticos caracterizando a hiperlíngua francesa da época muito mais do que o Levante otomano.

No entanto, esta não é a única característica desta construção discursiva, como veremos pela análise aprofundada de um relato específico, que nos permitirá avançar na análise das modalidades de construção do OdD.

\section{QUESTÕES DE MEMORIAS DISCURSIVAS}

\subsection{A MEMORIA MASCULINA: O CASO DE ABBE SEVIN}

Vamos agora apresentar um caso exemplar da construção do OdD, dando o exemplo das cartas que o Abade Sevin enviou, em 1728, ao Conde de Caylus, embaixador que já tinha tido a oportunidade de morar em Constantinopla. Famoso filólogo francês, o Abade, que era o protegido de Boileau, foi um dos estudantes da Academia de Inscrições e se aposentou
Cette évolution discursive caractérisait déjà l'enfermement du sultan, qui, dans les discours du XVIIème siècle, était représenté comme un idole vénéré par ses sujets, isolé tel un Dieu (RAUS, 2003a), tandis qu'au XVIIIème siècle le sérail devient plutôt (TOTT) « l'asile impénétrable (...du) despotisme », lieu où s'enferme un despote qui assujettit son peuple.

Si la construction discursive du sérail au XVIIIème siècle reste donc la même par rapport à l'enfermement, le point de vue des sujets-énonciateurs varie beaucoup. Tout comme il arrive pour le caravansérail, le sérail et, à son intérieur, l'appartement des femmes sont construits par rapport à la dénonciation des gouvernements despotiques caractérisant 1'hyperlangue française de l'époque beaucoup plus que le Levant ottoman.

Ce n'est pourtant pas la seule caractéristique de cette construction discursive, comme nous allons le voir par l'analyse approfondie d'un récit spécifique, qui nous permettra d'aller plus loin dans l'analyse des modalités de construction de l'OdD.

\section{Questions de mémoires discursives}

\subsection{La mémoire masculine : le cas de l'Abbé Sevin}

Nous allons maintenant présenter un cas exemplaire de la construction de l'OdD, en donnant l'exemple des Lettres que l'Abbé Sevin envoya en 1728 au Comte de Caylus, ambassadeur qui avait déjà eu la possibilité de séjourner à Constantinople. Célèbre philologue français, l'Abbé, qui était le protégé de Boileau, fut l'un des élèves de l'Académie des inscriptions et était à la 
durante a jornada que fez a Constantinopla por ordem do Rei para procurar manuscritos inéditos. Antes de iniciar a análise dessas Cartas, é necessário destacar que a forma epistolar é um gênero particular de discurso de viagem na medida em que, por um lado, se caracteriza pela copresença do componente literário e do componente científico e, por outro lado, supõe a interação do enunciador com o coenunciador. Destes dois aspectos resulta a conseqüência de que (RAUS, 2000a, p. 56):

o objeto (de discurso) que é mencionado nas cartas terá então um duplo status: de um lado, será posto e descrito como um referente do qual se fez a análise, de outro lado, será construído em discurso. Como um referente de que se fez a análise, o objeto cartas é apresentado em relação ao eixo vericondicional, isto é, em relação as suas condições de verdade e de acordo com modalidades de "transparência-opacidade" do dito; como um referente construído na prática discursiva, este objeto será elaborado a partir da interação dialógica entre o locutor e o destinatário das cartas.

Observemos que o par transparência-opacidade do dito remete à maneira como o enunciador modaliza a descrição do OdD, tentando limitar sua presença (transparência) ou, ao contrário, tentando acentuá-la como fonte de um ponto de vista direcionado sobre este objeto.

A leitura das cartas do Abade mostra que a descrição que ele faz de Constantinopla, do ponto de vista do referente, está fortemente ancorada no ponto de vista do enunciador. Assim como vimos em outros viajantes do século XVIII, o interdiscurso que caracteriza a cidade símbolo do Império Otomano bloqueia a descrição referencial, tanto que o coenunciador retraite lors du voyage qu'il fît à Constantinople par ordre du Roi pour aller chercher des manuscrits inédits. Avant d'entamer l'analyse de ses Lettres, il faut préciser que la forme de l'épistolaire est un genre particulier de discours de voyage, dans la mesure où d'une part, il se caractérise par la coprésence de la composante littéraire et de la composante scientifique, et de l'autre, il suppose l'interaction de l'énonciateur avec le co-énonciateur. De ces deux aspects découle la conséquence que (RAUS, 2000a, p. 56) :

l'objet (de discours) dont il est question
dans les lettres aura alors un double
statut: d'un côté il sera posé et décrit en
tant que référent dont on a fait
l'expérience, de l'autre il sera construit
en discours. En tant que référent dont on
a fait expérience, l'objet des lettres est
présenté par rapport à l'axe
vériconditionnel, c'est-à-dire par rapport
à ses conditions de vérité, et selon des
modalité de «transparence-opacité » du
dit; en tant que référent construit dans la
pratique discursive, cet objet sera
élaboré à partir de l'interaction
dialogique entre le locuteur et le
destinataire des lettres.

Précisons que le couple transparence-opacité du dit renvoie à la manière dont l'énonciateur modalise la description de l'OdD, en essayant de limiter sa présence (transparence) ou, à l'inverse, de l'accentuer comme source d'un point de vue porté sur cet objet.

La lecture des lettres de l'Abbé démontre que la description qu'il fait de Constantinople du point de vue du référent dont on fait l'expérience est fortement axée sur le point de vue de l'énonciateur. Tout comme on l'a vu pour d'autres voyageurs du XVIIIème siècle, l'interdiscours caractérisant la ville symbole de l'Empire ottoman bloque la description référentielle, d'autant plus que le co-énonciateur 
implicado aqui, o Conde de Caylus, tinha já estado em Constantinopla, o que permite Sevin privilegiar uma leitura « impressionista » da cidade (SEVIN, 1802):

\begin{abstract}
os minaretes de Constantinopla apareceram a minha vista. Nunca houve uma situação mais charmosa; não vou descrevê-los, vocês conhecem o país melhor do que eu. Parece-me mais conveniente entretê-los com o que acontece de mais curioso em Constantinopla.
\end{abstract}

O referente que surge não é a descrição dos lugares, mas sim a vida em Constantinopla e o que acontece lá de curioso, como o cortejo do embaixador de Ashart, que dá a possibilidade ao Abade de trazer julgamentos irônicos sobre o mundo otomano:

o essencial é nao não amolecer com essas pessoas que geralmente só tremem na frente daqueles que não têm firmeza e coragem.

[...] como você fez para não se aborrecer no mais desagradável dos países?

[...] Aqui não fazemos nenhum caso, nem virtude, nem bravura.

[...] Ninguém, certamente, pensou em procurar livros em um país tão bárbaro.

Esses poucos enunciados nos mostram que a cidade é descrita pela axiologia negativa. Sevin não se questiona sobre a verdade de seus julgamentos e de seu dito porque ele se apoia no coenunciador e na tradição masculina traçada pelos viajantes anteriores cujo único erro foi de não ter compreendido que a causa da barbarie otomana residia na presença de um governo despótico. É mais em relação à tradição literária, especialmente das "Mil e Uma Noites », que o Abade se posiciona para redesenhar a imagem de um Oriente pomposo durante a marcha concerné ici, le Comte de Caylus, a déjà fait un séjour à Constantinople, ce qui permet à Sevin de privilégier une lecture « impressionniste » de la ville (SEVIN, 1802) :
les minarets de Constantinople se sont présentés à ma vue. Jamais situation ne fut plus charmante; je ne vous ferai pas la description, vous connaissez le pays mieux que moi. Il me paraît plus convenable de vous entretenir de ce qui s'est passé de plus curieux à Constantinople.

Le référent qui en ressort n'est donc pas la description des lieux, mais plutôt la vie à Constantinople et ce qui y arrive de curieux, comme le cortège de l'ambassadeur d'Ashart, ce qui donne la possibilité à l'Abbé de porter des jugements ironiques sur le monde ottoman :

l'essentiel est de ne pas mollir avec ces gens, qui d'ordinaire ne tremblent que devant ceux qui manquent de fermeté et de courage.

[...] comment avez-vous fait pour ne vous pas ennuyer dans le plus vilain des pays?

[...] Ici on ne fait aucun cas ni de la vertu ni de la bravoure.

[...] Personne, certainement, ne s'est avisé de chercher des livres dans un pays aussi barbare.

Ces quelques énoncés nous montrent que la ville est décrite par l'axiologie négative. Sevin ne se pose même pas la question de la vérité de ses jugements et de son dit puisqu'il s'appuie sur le co-énonciateur et sur la tradition masculine dressée par les voyageurs précédents dont la seule erreur était de ne pas avoir compris que la cause de la barbarie ottomane résidait dans la présence d'un gouvernement despotique. C'est plutôt par rapport à la tradition littéraire, notamment aux Milles et une Nuits, que l'Abbé se positionne pour redresser l'image d'un Orient pompeux, 
do cortejo do embaixador de Ashart nas ruas de Constantinopla: "Eu estava imaginando ver uma amostra da magnificência de Darius e Xerxes. Que diferença!".

No nível enunciativo, a cidade descrita por Sevin é um espaço pintado à moda impressionista, em que o dito é modalizado e, por consequência, "opaco" em relação ao referente: a presença da modalização do enunciador é evidente $\mathrm{e}$ está centrada no enunciador que se coloca como origem do ponto de vista ("Eu vou confessar a você com franqueza ... Eu me imaginei ..."). Nessas modalidades de inscrição do sujeito no dito, podemos observar a presença de um "discurso autoritário" (ORLANDI, 1984,

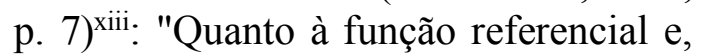
consequentemente, ao problema da verdade, eu diria que [...] no discurso autoritário, esta relação é determinada exclusivamente pelo locutor: a verdade é imposta".

$\mathrm{Na}$ verdade, a presença do coenunciador serve apenas para validar o dito do enunciador e seus julgamentos: "ele tinha distribuído alguns golpes, por alguns grandes chapéus brancos que você conhece [...] Você sabe que em Constantinopla cada bairro tem seus cachorros...".

Esta descrição "autoritária" de Constantinopla, que se baseia tanto na tradição de um discurso de viagem que agora se tornou legítimo quanto nos préconstruídos que consolidam a ideia de um Ocidente bárbaro, reforça a presença de uma memória discursiva que descreve a cidade, antes de tudo, por meio de curiosidades inéditas, principalmente, em relação às experiências das pessoas. Eis aqui, por exemplo, o que Paul Lucas dirá em seguida sobre este assunto, lors $\mathrm{du}$ défilement du cortège de l'ambassadeur d'Ashart dans les rues de Constantinople : «je m'étais imaginé voir un échantillon de la magnificence de Darius et de Xerxès. Quelle différence !».

Au plan énonciatif, la ville décrite par Sevin est un espace peint de manière impressionniste où le dit est modalisé, et par conséquent « opaque », par rapport au référent: la présence de la modalisation de l'énonciateur est évidente et est centrée sur l'énonciateur, qui se pose comme source du point de vue ( je vous avouerai franchement... je m'étais imaginé...»). Dans ces modalités d'inscription du sujet dans le dit, nous pouvons retracer la présence d'un «discours autoritaire »

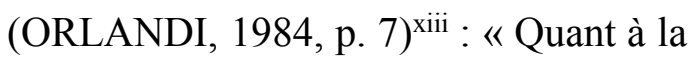
fonction référentielle et, par conséquent, au problème de la vérité, je dirais que [...] dans le discours autoritaire, cette relation est déterminée exclusivement par le locuteur : la vérité est imposée ».

En effet, la présence du coénonciateur ne sert que pour valider le dit de l'énonciateur et ses jugements : " il a été distribué quelques coups de poings, par certains grands bonnets blancs que vous connoissez [...] Vous savez que dans Constantinople chaque quartier a ses chiens... ».

Cette description « autoritaire » de Constantinople qui, s'appuie à la fois sur la tradition d'un discours de voyage qui s'est désormais légitimé et sur les préconstruits consolidant l'idée d'un Occident barbare, renforce la présence d'une mémoire discursive qui décrit la ville avant tout par des curiosités inédites, notamment par rapport au vécu des gens. Voici par exemple, ce que Paul Lucas dira ensuite à ce sujet, en faisant écho au dit de l'Abbé Sevin (LUCAS, 1719, p. 81-82) : 
fazendo eco ao dito do Abade Sevin (LUCAS, 1719, p. 81-82):

não tenho intenção de dar aqui uma relação desta capital do Império Otomano, nem dos costumes e da religião dos turcos, dos quais muitos Viajantes falaram; mas acrescentarei a suas histórias algumas peculiaridades que eles esqueceram.

E ainda, eis o que diria Pouqueville (1805, V-VI):

no segundo volume, onde falo de Constantinopla [...] cidade descrita por tantos viajantes, evitei repetir o que foi dito e posso afirmar que ofereço coisas novas.

A atenção dada às experiências das pessoas é tal que até encontramos o uso metonímico do nome próprio da cidade ("Constantinopla") para as pessoas que moram lá, como mostra o enunciado do Barão Tott (1785, vol. 128), "Constantinopla ficou consternada", citando o naufrágio de navios que deveriam garantir a chegada do trigo na cidade.

Essa memória forte, que se instala e é reiterada pelo Abade Sevin e pelos viajantes que partiram no século XVIII, é movimentada de fato pela tradução francesa das Cartas de uma senhora inglesa, Lady Mary Wortley Montague $^{\text {xiv }}$, que aparecerão em francês em 1763 em duas edições, uma publicada em Rotterdã e outra em Amsterdã, e que teve um sucesso incontestável de modo que foram posteriormente republicadas em várias edições e traduções diferentes, como veremos. A importância dessas Cartas reside no fato de que elas inauguram uma memória discursiva diferente em relação ao interdiscurso das narrativas masculinas, como observaremos. je n'ai pas dessein de donner ici une relation de cette capitale de l'Empire Ottoman, ni des mœurs \& de la Religion des Turcs, dont tant de Voyageurs ont parlé ; mais je joindrai à leur recits quelques particularitez qu'ils ont oubliées.

Et encore, voici ce qu'en dira Pouqueville (1805, V-VI):

dans le tome second, où je parle de
Constantinople [...] ville décrite par tant
de voyageurs, j'ai évité de répéter ce qui
avait été dit, et je puis affirmer que
j'offre des choses nouvelles.

L'attention portée au vécu des gens est telle que nous trouvons même l'utilisation métonymique du nom propre de la ville ( "Constantinople ») pour les personnes qui y habitent, comme le montre l'énoncé du baron de Tott (1785, vol. 1-28) «Constantinople fut consterné », en citant le naufrage de navires qui devaient assurer l'arrivée du blé dans la ville.

Cette mémoire forte, qui s'installe et est réitérée par l'Abbé Sevin et par les voyageurs qui partirent au XVIIIème siècle, est en fait basculée par la traduction française des Lettres d'une dame anglaise, Lady Mary Wortley Montague $^{\mathrm{xiv}}$ qui paraîtront en français en 1763 dans deux éditions, publiées l'une à Rotterdam et l'autre à Amsterdam, et qui eurent un succès indiscutables, au point qu'elles furent republiées ensuite dans plusieurs éditions et traductions différentes. L'importance de ces Lettres réside dans le fait qu'elles inaugurent une mémoire discursive différente par rapport à l'interdiscours des récits masculins, comme nous allons justement le voir. 


\subsection{A INAUGURAÇÃO DE UMA NOVA MEMORIA DISCURSIVA: AS CARTAS DE LADY MONTAGUE}

Esposa do embaixador inglês, Edward Montague, que partira em missão para o Levante otomano em 1716 e chegou a Constantinopla no ano seguinte, Lady Mary endereça suas cartas para um público variado que se compõe quase inteiramente de mulheres, com poucas exceções ${ }^{\mathrm{xv}}$. O OdD Constantinopla que essa viajante inglesa descreve é muito diferente daquele que tinha sido construído em discurso pelo Abade Sevin, mas também pela memória discursiva masculina instituída, que agora reproduzia descrições fixas dos lugares da principal cidade do Império otomano.

Em primeiro lugar, a cidade de Constantinopla dá a oportunidade a Lady Mary de se posicionar em relação ao interdiscurso e à memória consolidada por viajantes e historiadores, particularmente franceses ${ }^{\mathrm{xvi}}$, em relação ao OdD ${ }^{\mathrm{xvii}}$.

Me dá um prazer singular ler aqui as Relações do Levante. Elas são todas tão fabulosas, e repletas de absurdos, que me divertem infinitamente. Nenhum dos nossos viajantes não sentiu falta de lhes falar das mulheres turcas, certamente eles não viram nenhuma.

A descrição do espaço turco, especialmente da cidade de Constantinopla, se transforma então pela inauguração de uma nova memória que altera a anterior tanto que a legitimidade do dito dessa senhora inglesa pode se apoiar na experiência direta do referente, e isso diferentemente do que havia acontecido com seus antecessores, como ela destaca em uma carta dirigida a sua irmã Lady Mar, em 10 de março de 1718: "mas o que seria isso se eu fosse lhe dizer

\subsection{L'inauguration d'une nouvelle mémoire discursive : les Lettres de Lady Montague}

Femme de l'ambassadeur anglais Edward Montague, qui était parti en mission pour le Levant ottoman en 1716 et arrivé à Constantinople l'an suivant, Lady Mary adresse ses lettres à un public varié, qui se compose presqu'entièrement de femmes, à quelques exceptions près $^{\mathrm{xv}}$. L'OdD Constantinople que cette voyageuse anglaise décrit est un objet fort différent de celui qui avait été construit en discours par l'Abbé Sevin mais aussi par la mémoire discursive masculine instituée, qui désormais restituait des descriptions figées des lieux de la ville principale de l'Empire ottoman.

D'abord, la ville de Constantinople donne l'occasion à Lady Mary de se positionner par rapport justement à l'interdiscours et à la mémoire consolidée par les voyageurs et les historiens, notamment français ${ }^{\mathrm{xvi}}$, à l'égard de l'OdD ${ }^{\mathrm{xvii}}$ :

\footnotetext{
Je me fais un plaisir singulier de lire ici les Relations du Levant. Elles sont toutes si fabuleuses, et si remplie d'absurdités, qu'elles m'amusent infiniment. Pas un de nos voyageurs ne manque à vous parler des femmes turques, dont certainement ils n'ont vu aucune.
}

La description de l'espace turc, notamment de la ville de Constantinople, se transforme alors par l'inauguration d'une mémoire nouvelle, qui bascule la précédente, d'autant plus que la légitimité du dit de cette dame anglaise peut s'appuyer sur l'expérience directe du référent, et cela à la différence de ses prédécesseurs, comme elle précise dans une lettre adressée à sa sœur Lady Mar le 10 mars 1718 : «Mais que seroit-ce si j'allais vous dire que j'ai visité un 
que eu visitei um Harém?" $\mathrm{Na}$ verdade, ela teve a oportunidade de encontrar primeiro Sultana Hafiten ${ }^{\text {xviii }}$ e, depois, uma das favoritas do sultão, Fátima. O que é fundamental nestes encontros é primeiro o fato que ela retifica vários preconceitos decorrentes justamente de pré-construídos discursivos, como, por exemplo, aquele do confinamento de mulheres no serralho de que já falamos anteriormente, e sobre o qual Lady Mary dirá: "talvez não haja em todo o universo mulheres que gozem de maior liberdade". Observemos a presença da modalidade epistêmica da incerteza ("talvez"), o que já nos permite apresentar a hipótese de estar na presença de um posicionamento muito diferente do que o autoritário do Abade Sevin. O dito de Lady Mary é ainda mais inovador porque ela aprendeu o turco para conversar com mulheres turcas as quais encontrou justamente em Constantinopla e cujo diálogo transcreveu. Destacamos, em outro texto (RAUS, 2001b), a importância desta mudança da hiperlíngua e, por aí do interdiscurso sobre as narrativas de viagem e sobre o fato de que, finalmente, as mulheres turcas acessam à fala, seu discurso não sendo mais assim "silenciado" (ORLANDI, 1996, p. 50-51) xix $^{\text {. }}$

Se analisamos a relação com o referente, observamos que as descrições de Lady Mary também dizem respeito aos lugares e tentam limitar a presença do enunciador, modalizando muito pouco o dito, e esforçando-se para formulá-lo de maneira "transparente":

a segunda habitação, chamada Harém (o nome de Serralho é atribuído ao palácio do grande senhor), é o apartamento das Senhoras também ornado de uma galeria, da mesma maneira que todas as janelas, com vista para o jardim. [...] Todos os quartos são levantados por cerca de dois pés, por uma extremidade $[\ldots]$ é o que se chama aqui de sopha $[\ldots]$
Haram ? ». En effet, elle eut l'occasion de rencontrer d'abord la sultane Hafiten $^{\text {xviii }}$ et puis l'une des favorites du sultan, Fatima. Ce qui est fondamental, lors de ces rencontres, est d'abord le fait qu'elle redresse plusieurs préjugés, découlant justement des préconstruits discursifs, comme, par exemple, celui de l'enfermement des femmes dans le sérail, dont nous avons parlé précédemment et à propos duquel Lady Mary dira : " il n'est peut-être point des femmes dans tout l'univers, qui jouissent d'une plus grande liberté ». Remarquons la présence de la modalité épistémique de l'incertitude (" peut-être »), ce qui nous permet déjà d'émettre l'hypothèse d'être en présence d'un positionnement fort différent par rapport au dit autoritaire de l'Abbé Sevin. Le dit de Lady Mary est d'autant plus novateur qu'elle apprit le turc pour parler avec les femmes turques qu'elle rencontra justement à Constantinople et dont elle transcrira le dialogue. Nous avons souligné ailleurs (RAUS, 2001b) l'importance de ce changement de l'hyperlangue, et par-là de l'interdiscours concernant les récits de voyage, et le fait qu'enfin les femmes turques accèdent à la parole, leur discours n'étant donc plus «silencié » (ORLANDI, 1996, p. 50-51) ${ }^{\mathrm{xix}}$.

Si nous analysons la relation au référent, remarquons que les descriptions de Lady Mary concernent également les lieux et essaient de limiter la présence de l'énonciateur, en modalisant très peu le dit et en s'efforçant de le formuler de manière « transparente » :

le second logis, appellé Haram (le nom de Serrail est affecté au palais du grand seigneur), est l'appartement des Dames, orné aussi d'une galérie, de même que toutes les fenêtres, à vue sur le jardin. [...] Toutes les chambres sont relevées d'environ deux pieds, par un bout [...] c'est ce qu'on appelle ici le sopha $[. .$. C'est partout du brocard, ou du satin blanc brodé en or [...] Au milieu du 
Em toda parte, há brocado ou cetim branco bordado em ouro [...] No meio do jardim, está o Chiosk; nomeia-se assim um quarto espaçoso [...] as Senhoras passam muito tempo ali com bordados ou com música.

Observemos que o discurso de Lady Mary descreve os lugares em relação à alteridade ("é o que se chama aqui... nomeia-se assim ..."), lembrando deste ponto de vista as descrições que os viajantes haviam feito no século XVI. Além disso, os elementos do serralho que ela descreve são, em parte, aqueles que outros viajantes descreveram antes dela, como, por exemplo os sophas, os "quiosques", em relação aos quais analisamos a presença de configurações de enunciados (RAUS, 2000b). No entanto, observemos justamente que ela deixa falar as coisas e as pessoas por si mesmas, o que garante a transparência do seu dito. Entre outras coisas, notemos que ela, em relação aos seus coenunciadores, e diferentemente do Abade Sevin, não apenas privilegia a modalidade epistêmica da incerteza, mas também não impõe nada aos destinatários de suas cartas com os quais, ao contrário, ela estabelece algum tipo de troca para discutir a verdade do objeto, como se pode ver pelos exemplos a seguir (RAUS, 2000a, p. 63-64).

\begin{tabular}{|l|l|}
\hline \multicolumn{1}{|c|}{ Lady Mary } & \multicolumn{1}{|c|}{ Abbé Sevin } \\
\hline $\begin{array}{l}\text { Pergunto-lhes se a sua } \\
\text { conversa (turcos) } \\
\text { pode dar ao viajante } \\
\text { uma ideia justa do } \\
\text { espírito da nação. }\end{array}$ & $\begin{array}{l}\text { Eu admitirei a vocês } \\
\text { francamente que } \\
\text { muitos turcos } \\
\text { perderam parte de sua } \\
\text { gravidade, vendo } \\
\text { minha triste figura. }\end{array}$ \\
\hline $\begin{array}{l}\text { Você sabe o que se diz } \\
\text { em nosso país, que o } \\
\begin{array}{l}\text { sultão tem o costume } \\
\text { de jogar [...] ela }\end{array}\end{array}$ & $\begin{array}{l}\text { Você sabe que em } \\
\text { Constantinopla... } \\
\underline{\text { (Hafiten) }} \\
\underline{\text { assegurou que é um }} \\
\text { conto. }\end{array}$ \\
\hline
\end{tabular}

jardin est le Chiosk; on nomme ainsi une chambre spacieuse [...] les Dames y passent un grand temps ou à la broderie ou à la musique.

Précisons que le discours de Lady Mary décrit les lieux en relation justement à l'altérité (« ce qu'on appelle ici... on nomme ainsi...»), en rappelant de ce point de vue les descriptions que les voyageurs avaient faites au XVIème siècle. D'ailleurs, les éléments du sérail qu'elle décrit sont en partie ceux que d'autres voyageurs avaient décrits avant elle, comme par exemple les sophas, les « kiosques », à propos desquels nous avons analysé ailleurs la présence de configurations d'énoncés (RAUS, 2000b). Cependant, remarquons justement qu'elle laisse parler les choses et les personnes d'elles-mêmes, ce qui garantit la transparence de son dit. Remarquons, entre autres, que, par rapport à ses co-énonciateurs, et à la différence de l'Abbé Sevin, non seulement elle privilégie la modalité épistémique de l'incertitude mais aussi qu'elle n'impose rien aux destinataires de ses lettres avec lesquelles, au contraire, elle a une sorte d'échange pour discuter de la vérité de l'objet, comme lon peut le voir par les exemples suivants (RAUS, 2000a, p. 63-64).

\begin{tabular}{|c|c|}
\hline Lady Mary & Abbé Sevin \\
\hline $\begin{array}{l}\text { Je vous demande si } \\
\text { leur conversation (des } \\
\text { Turcs) peut donner à } \\
\text { un voyageur une juste } \\
\text { idée du génie de la } \\
\text { nation. }\end{array}$ & $\begin{array}{l}\text { Je vous avouerai } \\
\text { franchement que bien } \\
\text { des Turcs ont perdu } \\
\text { un peu de leur gravité, } \\
\text { en voyant ma triste } \\
\text { figure. }\end{array}$ \\
\hline $\begin{array}{l}\text { Vous savez ce qui se } \\
\text { dit chez nous, que le } \\
\text { sultan a coutume de } \\
\text { jeter } \quad(\ldots) \text { elle } \\
\text { (Hafiten) m'assura } \\
\text { que c'est un conte. }\end{array}$ & $\begin{array}{l}\text { Vous savez que dans } \\
\text { Constantinople... }\end{array}$ \\
\hline
\end{tabular}




\begin{tabular}{|c|c|}
\hline $\begin{array}{l}\text { Eu suponho que, nesta } \\
\text { proposta, você } \\
\text { acredita no auge de } \\
\text { seus desejos (Hafiten) } \\
\text { ao contrário, essas } \\
\text { mulheres... }\end{array}$ & $\begin{array}{l}\text { É preciso admitir a } \\
\text { você, minha surpresa } \\
\text { foi extrema. }\end{array}$ \\
\hline $\begin{array}{l}\text { Você terá lido, sem } \\
\text { dúvida, na maioria } \\
\text { das descrições que } \\
\text { nos deu da Turquia } \\
\text { que os edifícios [...] } \\
\text { com sua permissão eu } \\
\text { vou contradizer os } \\
\text { Senhores viajantes. }\end{array}$ & $\begin{array}{l}\text { Como você fez para } \\
\text { não se aborrecer no } \\
\text { mais desagradável } \\
\text { dos países? }\end{array}$ \\
\hline
\end{tabular}

Tab. 1: Comparação dos dizeres de Lady Mary e do Abade Sevin.

A tabela 1 mostra justamente a tendência de Lady Mary de corrigir preconceitos oriundos de pré-construídos do interdiscurso de viajantes anteriores apoiando-se na troca com 0 coenunciador. Seu dizer é, portanto, "polêmico" no sentido de que (ORLANDI, 1984, p. 7) "no discurso polêmico, a relação com a referência é respeitada, a verdade é disputada pelos interlocutores". Não somente isso, mas também as descrições interacionais obtidas pelo dizer restituído das mulheres (Hafiten e Fátima) permitirão desbloquear o sentido através da dinâmica descritiva operada em contexto (MONDADA 2000, p. 98).

A descrição do OdD é, portanto, muito diferente daquela do Abade Sevin, cujo discurso "autoritário" impõe a descrição de um lugar habitado por pessoas de quem não se recupera o dizer e em relação às quais se impõe uma verdade opaca.

\subsection{TENTATIVAS DE SILENCIAMENTO DA MEMORIA EXTERIOR}

A nova memória inaugurada por Lady Mary sobre o OdD, em que se

\begin{tabular}{|c|c|}
\hline $\begin{array}{l}\text { Je suppose qu'à cette } \\
\text { proposition vous la } \\
\text { croyez au comble de } \\
\text { ses vœux (Hafiten) } \\
\text { tout au contraire, ces } \\
\text { femmes... }\end{array}$ & $\begin{array}{l}\text { Il faut vous l'avouer, } \\
\text { ma surprise a été } \\
\text { extrême. }\end{array}$ \\
\hline $\begin{array}{l}\text { Vous aurez sans doute } \\
\text { lu, dans la plupart des } \\
\text { descriptions qu'on } \\
\text { nous donne de } \\
\text { Turquie que les } \\
\text { bâtiments (...) avec } \\
\text { votre permission je } \\
\text { donnerai la démenti à } \\
\text { Messieurs les }\end{array}$ & $\begin{array}{l}\text { Comment avez-vous } \\
\text { fait pour ne pas vous } \\
\text { ennuyer dans le plus } \\
\text { vilain des pays? }\end{array}$ \\
\hline
\end{tabular}

Tab. 1 : Comparaison des dits de Lady Mary et de l'Abbé Sevin.

Le tableau 1 montre justement la tendance de Lady Mary à rectifier les préjugés issus des préconstruits de l'interdiscours des voyageurs précédents en s'appuyant sur l'échange avec le coénonciateur. Son dit est donc " polémique » au sens où (ORLANDI, 1984, p. 7) « dans le discours polémique, la relation avec la référence est respectée, la vérité est disputée par les interlocuteurs ». Non seulement, mais les descriptions interactionnelles obtenues par le dit restitué des femmes (Hafiten et Fatima) permettront de débloquer le sens par la dynamique descriptive opérée en contexte (MONDADA 2000, p. 98).

La description de l'OdD est donc fort différente de celle de l'Abbé Sevin, dont le dit «autoritaire» impose la description d'un lieu habité par des personnes desquelles on ne restitue pas le dit et par rapport auxquelles on impose une vérité opaque.

\subsection{Tentatives de silenciement de la mémoire extérieure}

La nouvelle mémoire inaugurée par Lady Mary au sujet de l'OdD, dont 
descreve os lugares e as pessoas de forma transparente, movimenta totalmente a hiperlíngua francesa da época que não fica sem produzir reações. De fato, a forte memória do interdiscurso masculino gera uma contradiscurso que tenta, por um lado, silenciar o dizer de Lady Mary, deslegitimando ou refazendo-o, e, por outro lado, tenta impor a antiga descrição do OdD como o único válido. Vejamos os detalhes desses contradiscursos.

\subsubsection{A POLEMICA: O CASO DO BARÃO DE TOTT E DE POUQUEVILLE}

A primeira reação às novas descrições do OdD é aquela do barão de Tott que, partido ao Levante em 1755, utiliza a estratégia da desligitimação (I) ou a alternativa da concessão (II) para melhor desligitimar a nova memória incipiente:

(I) Refletindo sobre o que Milady Montague conta [...] eu encontro no gênio da língua e da nação turca o que deve lhe ter enganado [...].

(II) as ruas estão cheias de mulheres que vão e vem livremente para seus negócios; se os haréns mais fechados se abrem frequentemente para deixar o rebanho passear, não se deve concluir com M. Montague que as intrigas galantes acontecem nas lojas, onde às vezes as mulheres param.

A reformulação de mulheres por "rebanho" (II), que implicitamente implica a presença de um déspota que seria o guia das mulheres e do povo, e a retificação do dito servem para o barão deslegitimar a credibilidade da viajante inglesa.

A liberdade das mulheres turcas é, sem dúvida, o elemento discursivo constantemente questionado. Sobre este on décrit les lieux et les personnes de manière transparente, bascule tellement l'hyperlangue française de l'époque qu'elle ne reste pas sans produire des réactions. La mémoire forte de l'interdiscours masculin génère en effet un contre-discours qui essaie d'une part, de silencier le dit de Lady Mary, en le délégitimant ou en le remaniant, et de l'autre, d'imposer la vieille description de l'OdD comme la seule valable. Voyons donc les modalités de ces contrediscours.

\subsubsection{La polémique : le cas du baron de Tott et de Pouqueville}

La première réaction aux nouvelles descriptions de l'OdD est celle du baron de Tott qui, parti au Levant en 1755, utilise la stratégie de la délégitimation (I) ou, en alternative, de la concession (II) pour mieux délégitimer la nouvelle mémoire naissante :

(I) En réfléchissant sur ce que Milady Montague raconte [...] je retrouve dans le génie de la langue et de la nation turque ce qui a dû la tromper [...].

(II) les rues sont remplies de femmes qui vont et viennent librement pour leurs affaires ; si les harems les mieux fermés s'ouvrent souvent pour en laisser promener le troupeau, il ne faut pas en conclure avec $\mathrm{M}$. Montague que les intrigues galantes sont favorisées dans les boutiques, où les femmes s'arrêtent quelquefois.

La reformulation des femmes par « troupeau » (II), ce qui par l'implicite laisse entendre la présence d'un despote qui serait le guide des femmes et du peuple, ansi que la rectification du dit servent au baron pour délégitimer la crédibilité de la voyageuse anglaise.

La liberté des femmes turques est sans aucun doute l'élément discursif qui est remis sans cesse en question. À ce 
assunto, o barão de Tott chega a colocar em cena sua esposa como uma imagem refletida de Lady Mary. Como a viajante inglesa, Madame de Tott teria tido a oportunidade de encontrar as mulheres do harém, principalmente a sultana Asna. Observemos como a formulação proposta deste encontro acaba por bloquear a memória incipiente:

\begin{tabular}{|c|c|}
\hline Lady Mary & Mme de Tott \\
\hline $\begin{array}{l}\text { "Vocês são muito } \\
\text { libertas", } \\
\text { acrescentou [...] Eu } \\
\text { encontrei tanta justiça } \\
\text { e bom senso no que } \\
\text { ela me dizia, que }[\ldots] \\
\text { eu fui obrigada a } \\
\text { concordar que elas } \\
\text { tinham razão de } \\
\text { preferir os costumes } \\
\text { mahometanos aos } \\
\text { nossos que oferecem } \\
\text { uma mistura estranha } \\
\text { das máximas rígidas } \\
\text { do cristianismo com o } \\
\text { libertinismo dos } \\
\text { espartanos. }\end{array}$ & $\begin{array}{l}\text { as questões da } \\
\text { princesa [a sultana] se } \\
\text { concentraram sobre a } \\
\text { liberdade que nossas } \\
\text { mulheres desfrutam. } \\
\text { Ela fez uma } \\
\text { comparação com os } \\
\text { costumes do Harém ... } \\
\text { ela acabou } \\
\text { concordando sobre as } \\
\text { vantangens que } \\
\text { resultam de nossos } \\
\text { costumes... ela se } \\
\text { lamenta pela } \\
\text { barbaridade que a } \\
\text { entregara aos treze } \\
\text { anos para um homem } \\
\text { muito mais velho. }\end{array}$ \\
\hline
\end{tabular}

Tab. 2: Embate entre memórias discursiva: o dizer de Lady Mary e a retificação de Madame de Tott.

A Tabela 2 mostra o dizer refletido das duas senhoras, aquilo que serve a Madame de Tott para retificar o dizer da viajante inglesa que a precedeu na visita do harém.

Alguns anos depois, em 1797, outro viajante, Pouqueville, marca de maneria clara seu posicionamento no interdiscurso, invalidando o dizer de Lady Mary:

Nunca ouvi dizer, ainda que o assegure Milady Montaigu [...]. Essa é ainda uma das belas ficções de sua viagem [...]. Eu tinha lido, há algum tempo, Milady Montagu, e pensei que iria encontrar [dentro da residência da sultana] paredes encrustadas com esmeraldas e safiras, sujet, le baron de Tott arrive à mettre en scène sa femme en tant que double spéculaire de Lady Mary. Tout comme la voyageuse anglaise, Madame de Tott aurait eu l'occasion de rencontrer les femmes du harem, notamment la sultane Asna. Voyons comment la formulation proposée de cette rencontre finit par bloquer la mémoire naissante :

\begin{tabular}{|c|c|}
\hline Lady Mary & Mme de Tott \\
\hline «Vous êtes & les questions de la \\
\hline libertines $»$, ajoutait- & Itane] \\
\hline elle & port \\
\hline tant de justesse et de & dont \\
\hline sens dan & jouissen \\
\hline qu' & $\mathrm{col}$ \\
\hline$[\ldots]$ je fus obligée de & usages du \\
\hline convenir & tomba d'accord \\
\hline raison & tage \\
\hline préférer les mœurs & devait résulter de nos \\
\hline Mahométanes à nos & lle se \\
\hline usages qui & ia sur la barbarie \\
\hline mé & qui l'as \\
\hline maximes & treize \\
\hline Chri & vieillard. \\
\hline liber & \\
\hline Spar & \\
\hline
\end{tabular}

Tab. 2 : lutte entre mémoires discursives : le dit de Lady Mary et la rectification de Mme de Tott.

Le tableau 2 montre le dit spéculaire des deux dames, ce qui sert à Mme de Tott pour rectifier le dit de la voyageuse anglaise qui l'a précédée dans la visite du harem.

Quelques années plus tard, en 1797, un autre voyageur, Pouqueville marque de manière claire son positionnement dans l'interdiscours, en invalidant le dit de Lady Mary :

Je n'ai jamais entendu dire, ainsi que l'assure Milady Montaigu [...] C'est encore une des jolies fictions de son ouvrage $[. .$.$] .$

J'avais lu autrefois Milady Montagu, et je croyais bonnement que j'allais trouver [à l'intérieur de la résidence de la 
jardins emoldurados de flores e, enfim, o palácio voluptuoso de Armide. Eu amaldiçoava de boa-fé essa mulher que tirou sua viagem de sua brilhante imaginação. [...]

[depois de ter conseguido entrar no harém] é preciso dizer, não há nada miserável no mobiliário deste harém [...]. Isso prova que Milady Montaigu nunca tinha entrado nesse lugar. [...] Nós saímos do harém na ponta dos pés. Nosso cicerone nos assegurou que éramos os únicos europeus que haviam entrado ali até agora.

Como médico, Pouqueville teria tido o privilégio de visitar um harém, o que o colocaria na condição de invalidar o dizer de Lady Mary através de um contradiscurso legitimado pela experiência direta do referente em questão.

Como se pode observer nos enunciados citados, assiste-se aí a um verdadeiro conflito entre a forte memória de um discurso autoritário e uma memória inicial que permanece fraca porque é polêmica e feminina ao mesmo tempo. O OdD se encontra modificado. Ao referente modalizado de maneira negativa em relação ao Ocidente e que, apoiando-se em pré-construídos, acaba insistindo sobre a falta de felicidade de um povo que no século XVIII é considerado como assujeitado a um déspota, opõe-se um referente compreendido como outro, como um espaço de sentido novo a (re)descobrir.

\subsubsection{AS TRADUÇÕES FRANCESAS DAS CARTAS DE LADY MARY}

As tentativas de deslegitimar o discurso de Lady Mary, realizadas pelos viajantes do século XVIII, não chegaram realmente a atingir o objetivo de tornar inoperante a memória emergente que se sultane] des murs incrustés d'émeraudes et de saphirs, des parterres émaillés de fleurs, enfin le palais voluptueux d'Armide. Je maudissais de bonne foi cette femme, qui tira son voyage de son imagination brillante. [...]

[après avoir réussi à pénétrer dans le harem] il faut le dire, il n'y a rien que de pitoyable dans les ameublements de ce harem [...] Cela prouve que Milady Montaigu n'avait jamais pénétré dans cet endroit. [...] Nous sortîmes du harem sur la pointe du pied. Notre introducteur nous assura que nous étions les seuls Européens qui y eussent jusqu'à ce jour pénétré.

En tant que médecin, Pouqueville aurait eu le privilège de visiter un harem, ce qui le mettrait en condition d'invalider le dit de Lady Mary par le biais d'un contre-discours légitimé par l'expérience directe du référent concerné.

Comme on peut le voir par les énoncés cités, nous assistons à un véritable conflit entre la mémoire forte d'un dit autoritaire et une mémoire naissante qui reste faible parce que polémique et féminine à la fois. L'OdD s'en trouve modifié. $\mathrm{Au}$ référent modalisé de manière négative par rapport à l'Occident et qui, tout en s'appuyant sur des préconstruits, finit par insister sur le manque de bonheur d'un peuple qui, au XVIIIème siècle, est considéré comme assujetti à un despote, s'oppose un référent perçu comme autre, comme un espace de sens nouveau à (re)découvrir.

\subsubsection{Les traductions françaises des Lettres de Lady Mary}

Les tentatives de délégitimer le dit de Lady Mary opérées par les voyageurs du XVIII ${ }^{\mathrm{e}}$ siècle n'arrivent pas à atteindre vraiment la visée de rendre inopérante la mémoire émergente 
supunha ser heterogênea. Aqui, abaixo, vejamos o que podemos ler sobre esse viajante na Biografia universal antiga e moderna publicada no século seguinte:

Ela obteve permissão do Sultão Ahmet para entrar no serralho, onde fez amizade com a Sultana favorita, Fatima. As frequentes visitas levaram-na a corrigir muitos preconceitos e possibiltiaram a ela dar ideias mais aproximadas do harém do grande senhor que os europeus não tinham tido até ela.

Entretando, outro meio mais sútil parece operar tentativas de silenciamento do dito saturado. As Cartas inglesas foram traduzidas para o francês em 1763 . Se as primeiras traduções de Amsterdã e Roterdã estão muito próximas do original e permanecem, portanto, muito fiéis ao discurso de Lady Mary, as traduções posteriores reformulam fortemente o discurso da viajante inglesa. Observemos aqui, abaixo, o que Voltaire dizia sobre este assunto a D'Argenson, em uma de suas cartas (VOLTAIRE, 1843, p. 347): "Se elas [as Cartas de Lady Mary] estão bem traduzidas (o que é muito difícil), você ficará encantado ao ver coisas curiosas e novas, embelezadas pela ciência, pelo gosto e pelo estilo".

E depois, em outra carta, desta vez dirigida aos autores da Gazette littéraire (VOLTAIRE, 1821, p. 336): "aqueles [os leitores das Cartas] que só as conhecem pelas traduções francesas que apareceram até agora, não saberiam formar uma ideia justa".

E, ainda, em uma Carta da Correspondência Grimm e Diderot, lemos que (Correspondência..., p. 209): "apesar da tradução obscura que se fez aqui dessas cartas, há alguns anos atrás, qui est censée être hétérogène. Voici ce que nous pouvons lire de cette voyageuse dans la Biographie universelle ancienne et moderne au siècle suivant :

Elle obtint du sultan Ahmet la permission d'entrer dans le sérail, où elle se lia d'amitié avec la sultane favorite Fatima. Les fréquentes visites qu'elle lui fit, la mirent à la portée de redresser bien des préjugés, et de donner, du harem du grand-seigneur, des idées plus justes que les Européens n'en avaient eu jusqu'à elle.

Pourtant, un autre moyen plus subtil semble opérer des tentatives de silenciement du dit encombrant. Les Lettres anglaises furent traduites en français en 1763. Si les toutes premières traductions d'Amsterdam et de Rotterdam sont somme toute très proches de l'original et restent donc assez fidèles au dit de Lady Mary, les traductions postérieures remanient fortement le dit de la voyageuse anglaise. Voici ce que Voltaire précisait à ce sujet à D'Argenson dans l'une de ses lettres (VOLTAIRE, 1843, p. 347) : «si elles [les Lettres de Lady Mary] sont bien traduites (ce qui est fort difficile), vous serez enchantés de voir des choses curieuses et nouvelles, embellies par la science, par le goût, et par le style ».

Et puis dans une autre lettre, cette fois-ci adressée aux auteurs de la Gazette littéraire (VOLTAIRE, 1821, p. 336): " [c]eux [les lecteurs des Lettres] qui ne les connaissent que par les traductions françaises qui en ont paru jusqu'à présent, ne sauraient s'en former une juste idée ».

Et encore, dans une Lettre de la Correspondance de Grimm et Diderot nous lisons que (Correspondência..., p. 209) : « [m]algré la traduction maussade qu'on a faite ici de ces lettres, il y a 
elas tiveram o maior sucesso e grande mérito ».

Em 1805, Pierre Hubert Anson decidiu retraduzir as Cartas, julgando as traduções anteriores precisas mas também incorretas na medida que tinham alterado o estilo de Lady Mary. Além disso, bastava-se lançar os olhos nos prefácios das primeiras traduções e nas seguintes, para observar as mudanças de posicionamento do tradutor após as primeiras edições de 1763. A seguir, acompanhemos o que diz o tradutor da primeira tradução de Lady Mary feita em Amsterdã em 1763 (MONTAGUEWORTLEY, 1763, I-II):

Encontra-se aqui a descrição de suas viagens, mil traços curiosos, algumas anedotas picantes, boas observações sobre os costumes [...] Isso que a Sra. Montague diz sobre a cidade de Viena, dos François, da religião romana \&c. não é nada menos que obrigatório: os povos, seus próprios preconceitos, reais ou supostos, têm direito a considerações.

E aqui, por outro lado, está o que o padre dominicano Jean Brunet diz em sua tradução de 1764 (MONTAGUEWORTLEY, 1764b, VI):

Milady Montagutes se ocupou de desenvolver o caráter, de conhecer os costumes de cada Nação; [...] de fato, vemos através de suas cartas que nada escapava a sua crítica: é verdade que podemos acusá-la por ser pouco dada à prevenção: o que ela diz de Viena, de Genes \& de Paris, parece uma sátira ditada pelo ódio.

Se o tradutor de Amsterdã justifica o discurso de Lady Mary pela presença de um referente que merece ser restituído tal e qual, Brunet atribui os quelques années, elles ont eu le succès le plus grand et le mieux mérité ».

En 1805, Pierre Hubert Anson décide justement de retraduire les Lettres, jugeant les traductions précédentes comme exactes mais aussi fautives dans la mesure où elles avaient finit par altérer le style de Lady Mary. D'ailleurs, il suffit de jeter un coup d'œil aux préfaces des premières traductions et des suivantes, pour remarquer les changements de positionnement du traducteur après les premières éditions de 1763. Voici ce que dit le traducteur de la toute première traduction de Lady Mary faite à Amsterdam en 1763 (MONTAGUE-WORTLEY, 1763, I-II) :

On y trouve la description de ses
voyages, mille traits curieux, quelques
anecdotes piquantes, de bonnes
observations sur les mœurs [...] Ce que
Mme de Montague dit de la ville de
Vienne, des François, de la Religion
Romaine \&c. n'est rien moins
qu'obligeant: les peuples, leurs préjugés
mêmes, réels ou supposés, ont droit à des
égards.

Et voici, par contre, ce qu'en dit le Père dominicain Jean Brunet dans sa traduction de 1764 (MONTAGUEWORTLEY, 1764b, VI) :

Milady Montagutes s'occupoit à
développer le caractère, à connoître les
mours de chaque Nation ; $(.$.$) en effet,$
l'on voit par ses lettres que rien
n'échappoit à sa critique : $\underline{\text { il est vrai }}$
qu'on peut lui reprocher de s'être un peu
trop livrée à la prévention : ce qu'elle dit
de Vienne, de Gènes \& de Paris,
ressemble à une satyre dictée par la
haine.

Si le traducteur d'Amsterdam justifie le dit de Lady Mary par la présence d'un référent qui mérite d'être restitué tel quel, Brunet attribue les préjugés non pas aux peuples décrits 
preconceitos não aos povos descritos, mas à escrita da viajante inglesa.

Além disso, a tradução de Brunet tem sido constantemente contestada. Aqui estão alguns enunciados do negociante de Marselha, Sr. Guys, que também tinha feito uma viagem ao Levante e que, aproveitando a publicação do $3^{\circ}$ volume francês das Cartas (1768), incluiu nele várias observações interessantes (MONTAGUEWORTLEY, 1768, p. 104 e 147):

Eu acredito que o texto neste lugar foi alterado pelo Tradutor [...] Milady não acreditou, como o Sr. de T ... [Tott] afirma, que todas as casas [...].

O Tradutor de Milady escreveu que os Fauxburgs de Pera, de Tophana \& de Galata são habitados apenas por Cristãos Franceses, e não por Francos, como o Sr. de T... [Tott] repete: quanto maior o absurdo, mais a falha do Tradutor é visível.

A defesa da memória fraca do discurso de Lady Mary se faz precisamente pela deslegitimação do tradutor mas também de um de seus detratores: o Barão Tott.

De qualquer forma, a análise da tradução de Brunet mostra que o Abade silencia certas partes do discurso de Lady Mary e transforma outras. Por exemplo, aqui está um fragmento inteiro que não está traduzido por Brunet, mas que é fundamental nas Cartas, na medida em que permite a Lady Mary posicionar-se como viajante ("nós viajantes"), o que leva à legitimação de seu discurso pelo interdiscurso e a enfatizar a veracidade de suas palavras (MONTAGUEWORTLEY, 1799, p. 220):

We travellers are in very hard circumstances. If we say nothing but what has been said before us, we are mais à l'écriture de la voyageuse anglaise.

D'ailleurs, la traduction de Brunet a été souvent contestée. Voici quelques énoncés tirés du négociant marseillais M. Guys, qui avait fait lui aussi un voyage au Levant et qui, profitant de la parution du $3{ }^{\text {ème }}$ volume français des Lettres (1768), y inclut plusieurs intéressantes (MONTAGUEWORTLEY, 1768, p. 104 et 147) :

Je croirois que le texte en cet endroit a été altéré par le Traducteur [...] Milady ne croyoit donc pas, comme M. de T... [Tott] le prétend, que toutes les maisons [...].

Le Traducteur de Milady a écrit que les Fauxbourgs de Pera, de Tophana, \& de Galata, ne sont habités que par des Chrétiens François, \& non par des Francs, comme M. de T... [Tott] le repète : plus l'absurdité est grande, plus la faute du Traducteur est visible.

La défense de la mémoire faible du dit de Lady Mary se fait justement par la délégitimation du traducteur mais aussi de l'un de ses détracteurs : le baron de Tott.

En tous les cas, l'analyse de la traduction de Brunet démontre que l'Abbé silencie certaines parties du dit de Lady Mary et en transforme d'autres. Voici, par exemple, un extrait entier qui n'est pas traduit par Brunet et qui, par contre, est fondamental dans les Lettres dans la mesure où il permet à Lady Mary de se positionner comme voyageuse («we travellers»), ce qui aboutit à la légitimation de son dit par l'interdiscours et de souligner la véracité de ses propos (MONTAGUE-WORTLEY, 1799, p. 220) :

We travellers are in very hard circumstances. If we say nothing but what has been said before us, we are 
dull, and we have observing nothing. If we tell any thing new, we are laughed at as fabolous : and romantic, not allowing either for the difference of ranks, which affords difference of company, or more curiosity, or the change of customs, that happens every twenty years in every country. But the truth is, people judge of travellers, exactly with the same candour, good nature, and impartiality, they judge of their neighbours upon all occasions. For my part, if I live to return amongst you, I am so well acquainted with the morals of all my dear friends and acquaintances, that I am resolved to tell them nothing at all, to avoid the imputation (wich their charity would certainly incline them to) of my telling too much. But I depend upon you knowing me enough, to believe whatever I seriously assert for truth; though I give you leave to be surprised at an account so new to you.

Além do silenciamento do discruso, que aqui produz uma verdadeira censura pela omissão, Brunet também opera reflexões interessantes, transformando o discurso polêmico de Lady Mary em autoritário, como podemos ver por alguns exemplos:

\begin{tabular}{|c|c|}
\hline Original inglês & Tradução de Br \\
\hline $\begin{array}{l}\text { (p. 2) you may see } \\
\text { Dutch maids wash } \\
\text { the pavement of } \\
\text { street. }\end{array}$ & $\begin{array}{l}\text { (vol. 1, p. 11) Enfim, as } \\
\text { ruas da Holanda são } \\
\text { mais limpas que nossos } \\
\text { quartos de dormir. }\end{array}$ \\
\hline $\begin{array}{l}\text { (p. 68) You may eas } \\
\text { imagine I was then } \\
\text { great a hurry to anwer }\end{array}$ & $\begin{array}{l}\text { (vol. 1, p. 107) Minhas } \\
\text { preocupações não } \\
\text { permitem responder. }\end{array}$ \\
\hline $\begin{array}{l}\text { (p. 217) You may } \\
\text { sure, that they w } \\
\text { spoiled. }\end{array}$ & vol. 2, p. 80) Estavam \\
\hline
\end{tabular}

Tab. 3: Transformação do discurso polêmico em discurso autoritário na tradução de Brunet.

Brunet não é o único a intervir com tentativas de silenciamento do discurso compreendido como alógeno em relação à memória "tecida" por homens em torno do OdD. Sobre este assunto, destacamos, para finalizar, que a dull, and we have observing nothing. If we tell any thing new, we are laughed at as fabolous : and romantic, not allowing either for the difference of ranks, which affords difference of company, or more curiosity, or the change of customs, that happens every twenty years in every country. But the truth is, people judge of travellers, exactly with the same candour, good nature, and impartiality, they judge of their neighbours upon all occasions. For my part, if I live to return amongst you, I am so well acquainted with the morals of all my dear friends and acquaintances, that I am resolved to tell them nothing at all, to avoid the imputation (wich their charity would certainly incline them to) of my telling too much. But I depend upon you knowing me enough, to believe whatever I seriously assert for truth; though I give you leave to be surprised at an account so new to you.

Outre le silenciement du dit, qu'ici produit une véritable censure par l'omission, Brunet opère également des remaniements intéressants, en transformant le dit polémique de Lady Mary en autoritaire, comme nous pouvons le voir par ce quelques exemples :

\begin{tabular}{|c|c|}
\hline Original anglais & Traduction de Brunet \\
\hline $\begin{array}{l}\text { (p. 2) you may see the } \\
\text { Dutch maids washing } \\
\text { the pavement of the } \\
\text { street. }\end{array}$ & $\begin{array}{l}\text { (vol. 1, p. 11) Enfin, les } \\
\text { rues de Hollande sont } \\
\text { plus propres que nos } \\
\text { chambres à coucher. }\end{array}$ \\
\hline $\begin{array}{l}\text { (p. 68) You may easily } \\
\text { imagine I was then in } \\
\text { great a hurry to anwer } \\
\text { it. }\end{array}$ & $\begin{array}{l}\text { (vol. 1, p. 107) } \\
\text { préoccupations } \\
\text { permirent pas d'y } \\
\text { répondre. }\end{array}$ \\
\hline $\begin{array}{l}\text { (p. 217) You may be } \\
\text { sure, that they were } \\
\text { spoiled. }\end{array}$ & $\begin{array}{l}\text { (vol. 2, p. 80) elles } \\
\text { furent toutes gâtées. }\end{array}$ \\
\hline
\end{tabular}

Tab. 3 : transformation du dit polémique en dit autoritaire dans la traduction de Brunet.

Brunet n'est pas le seul à intervenir par des tentatives de silenciement du dit ressenti comme allogène par rapport à la mémoire «tissée » par les hommes autour de l'OdD. À ce sujet, signalons, pour finir, que la réédition anglaise de 1767 , avec 
reedição inglesa de 1767, com o acréscimo de seis Cartas, que serão traduzidas na França por Suard em 1768 e que provavelmente são falsas, exceto por uma carta escrita em francês ${ }^{x x}$, apresentam, por sua vez, revisões interessantes. Esta nova edição do epistolário de Lady Mary nos interessa especialmente pela inserção de uma carta dirigida a Alexander Pope e que, já em inglês, denuncia mais uma vez a vontade de retificar o dito saturado (MONTAGUE-WORTLEY, 1799, p. 333):

The women here are not, indeed, so closely confined as many have related; they enjoy a high degree of liberty, even in the bottom of serviture [...] but, after all, they are still under uneasy apprehensions of being discovered, and a discovery exposes them to the most merciless rage of jealous, wich is here a monster that cannot be satiated but with blood.

\section{CONCLUSÕES}

Em conclusão, Constantinopla é um espaço que é descrito no século XVI por percursos que privilegiam lugares percebidos como outros, lugares que, entre outros, são povoados por pessoas de quem se descreve as roupas e os costumes. No entanto, a partir do século XVIII, a cidade se torna um espaço de sentido saturado que favorece, por um lado, a vontade de descrever apenas as coisas curiosas, "pitorescas" (no sentido de "digno de ser pintado"), inéditas, especialmente em relação às pessoas que lá se pode encontrar e, por outro lado, o surgimento de juízos de valor em relação a um referente que é considerado bárbaro, porque submentido ao regime de um déspota. Esta forte memória interdiscursiva, que se baseia em uma longa tradição e conduz a uma leitura impressionista do $\mathrm{OdD}^{\mathrm{xxi}}$, enquadra $\mathrm{o}$ l'ajout de six Lettres, qui seront traduites en France par Suard en 1768 et qui sont sans doute fausse à l'exception d'une lettre rédigée en français ${ }^{\mathrm{xx}}$, opèrent à leur tour des remaniements intéressants. Cette nouvelle édition de l'épistolaire de Lady Mary nous intéresse surtout par l'ajout d'une Lettre adressée à Alexander Pope et qui, déjà en anglais, dénonce encore une fois la volonté de rectifier le dit encombrant (MONTAGUEWORTLEY, 1799, p. 333) :

\section{Conclusions}

En conclusion, Constantinople est un espace qui est décrit au XVIème siècle par des parcours qui privilégient les lieux perçus comme autres, lieux qui, entre autres, sont peuplés par des gens dont on décrit les vêtements et les mœurs. Cependant, à partir du XVIIIème siècle, la ville devient un espace de sens saturé, ce qui favorise d'une part, la volonté d'en décrire les seules choses curieuses, « pittoresques» (au sens de « dignes d'être peintes »), inédites, notamment par rapport aux personnes qu'on $y$ rencontre, et de l'autre, la parution de jugement des valeurs par rapport à un référent qui est considéré comme barbare, parce que subissant le régime d'un despote. Cette mémoire interdiscursive forte, qui s'appuie sur une longue tradition et qui débouche sur une lecture impressioniste de l'OdD $^{\mathrm{xxi}}$, 
dito por um pré-construído reconfortante e ideológico. Este pré-construído aprisiona o OdD em um discurso que bloqueia o sentido, contribuindo para a naturalização da memória em questão.

Essa memória é contudo movimentada, durante a segunda metade do século XVIII, pela emergência de uma memória alógena, exterior, vinda de outro lugar e pelo intermédio de uma voz feminina que se posiciona contra os préconstruídos e deixa aberta novas possibilidades de sentido. O OdD se encontra transformado. A luta de memórias discursivas opostas não chega a silenciar o dito polêmico de Lady Mary, que finalmente se imporá no século XIX, renovando a percepção da cidade de Constantinopla, agora concebida como espaço-outro, animada por pessoas especialmente por mulheres, que adquirem o direito de falar e que, desta maneira, liberam-se de préconstruídos.

A história da construção de um objeto de discurso permite assim acompanhar de perto a controvérsia entre duas memórias diferentes e mostra até que ponto é no interdiscurso que não apenas o sentido, mas também as categorias conceituais acabam permanecendo nos pré-construídos antes mesmo de fazer a análise do objeto. Em alguns tipos de guias turísticos ante litteram, em relação aos quais continuam, entretanto, muito diferentes, as narrativas dos séculos XVI-XVII acabam condicionando as produções discursivas do século XVIII pelo préconstruído, isso obriga os novos viajantes a se posicionar em relação à tradição do discurso de viagem mas permite-lhes também legitimar o discurso de viagem como um tipo de discurso à parte, dispondo de uma memória que vem de seu interior. encadre le dit par un préconstruit rassurant et idéologique. Ce préconstruit enferme l'OdD dans un discours qui en bloque le sens, contribuant à la naturalisation de la mémoire en question.

Cette dernière est pourtant basculée, pendant la seconde moitié du XVIIIème siècle, par l'émergence d'une mémoire allogène, extérieure, venant d'ailleurs et par l'intermédiaire d'une voix féminine qui se positionne contre les préconstruits et laisse ouvertes de nouvelles possibilités de sens. L'OdD s'en trouve transformé. La lutte de mémoires discursives opposées n'arrive pas à silencier le dit polémique de Lady Mary, qui finalement s'imposera au XIXème siècle, en renouvelant la perception de la ville de Constantinople, conçue maintenant comme un espaceautre, animé par des personnes, notamment les femmes, qui acquièrent le droit à la parole et qui, de cette manière, s'acquittent des préconstruits.

L'histoire de la construction d'un objet de discours permet donc de suivre de près la polémique entre deux mémoires différentes et montre jusqu'à quel point c'est dans l'interdiscours que non seulement le sens mais également les catégories conceptuelles finissent par rester prises dans les préconstruits avant même de faire l'expérience de l'objet. Sorte de guides touristiques ante litteram, par rapport auxquels ils restent pourtant fort différents, les récits du XVI-XVIIème siècles finissent par conditionner les productions discursives du XVIIIème siècle par le préconstruit, ce qui oblige les nouveaux voyageurs à se positionner par rapport à la tradition $\mathrm{du}$ discours de voyage mais qui leur permet également de légitimer le discours de voyage comme type de discours à part, disposant d'une mémoire venant de son intérieur. 
No século XIX, o guia turístico herdará justamente este discurso (KEBRAT-ORECCHIONI, 2004, p. 134) para construir outros objetos "pitorescos".
$\mathrm{Au}$ XIXème siècle, le guide touristique héritera justement de ce discours (KEBRAT-ORECCHIONI, 2004, p. 134) pour construire d'autres objets « pittoresques ».

\section{REFERENCIAS}

AA.VV. (1988). « L'orientalisme au XVIIème et XVIIème siècles », Civilisation, Paris : Presses de la Sorbonne, $\mathrm{n}^{\circ} 15$.

AUROUX, Sylvain (1997). « La réalité de l'hyperlangue ». Langages, n 31, p. 110-121.

BERTY, Valéry (1995). Les récits de voyage français en Orient au XIXe siècle - un essai de typologie narrative, Thèse de $3^{\text {ème }}$ cycle, Université de Lille III.

CHARAUDEAU, P.; MAINGUENEAU, D. (2002). Dictionnaire d'analyse du discours. Paris : Seuil.

CORRESPONDANCE LITTERAIRE, philosophique et critique de Grimm et de Diderot depuis 1753 jusqu'en 1769. (1814). Londres : Colburne.

COURTINE, Jean-Jacques (1981). «Quelques problèmes théoriques et méthodologiques en analyse du discours, à propos du discours communiste adressé aux Chrétiens ». Langages, $n^{\circ} 62$, p. 9-128.

FIORENTINO, Francesco (1982), Dalla geografia all'autobiografia: Viaggiatori francesi in Levante. Padoue : Antenore.

HENRY, Paul (1975). « Constructions relatives et articulations discursives ». Langages, n'37, p. 81-98.

KEBRAT-ORECCHIONI, Catherine (2004). " Suivez le guide! Les modalités de l'invitation au voyage dans les guides touristiques: l'exemple de l' 'île d'Aphrodite' ». In: BAIDER, F.; BURGER, M.; GOUTSOS, D. (eds). La communication touristique. Approches discursives de l'identité et de l'altérité. Paris: L'Harmattan. p. 133-150.

MAINGUENEAU, Dominique (1984). Genèse du discours. Liège : Mardaga.

MARTINO, Pierre (1906). L'Orient dans la littérature française au XVIIe et au XVIIIe siècle. Paris : Hachette.

LORENZA, Mondada. (2000). Décrire la ville. La construction des savoirs urbains dans l'interaction et dans le texte. Paris : Anthropos.

(1994). Verbalisation de l'espace et fabrication du savoir. Approche 
linguistique de la construction des objets de discours. Lausanne : Université de Lausanne.

PAVEAU, Marie-Anne. (2015). « Les paroles antérieures selon Jean Peytard. Tiersparlant et masse interdiscursive ». https://hal-univ-paris13.archives-ouvertes.fr/hal01163506/document.

. (2013). « Mémoire, démémoire, amémoire. Quand le discours se penche sur son passé ». https://hal.archives-ouvertes.fr/hal-00990033/document

(2006). Prédiscours : sens, mémoire, cognition. Paris : Presses de la Sorbonne Nouvelle.

ORLANDI, Eni Puccinelli. (1984). « Typologie du discours et règles de la conversation ». Langage \& Société, n ${ }^{\circ}$. 29, p. 3-25.

. (1996) Les formes du silence. Dans le mouvement du sens. Traduction de Pierre Léglise-Costa, avec révisions d'Eni Puccinelli Orlandi, de Francine Mazière et d'André Collinot. Paris : Édition des Cendres. [Texte original : (1992) As formas do silêncio : no movimento dos sentidos. Campinas : Editora da Unicamp.]

(2015 [1999]). Análise de discurso. Campinas : Pontes.

RAUS, Rachele. (2017). " Préface ». In : RAUS, Rachele ; CAPPELLI, Gloria ; FLINZ, Carolina (éds.). Le guide touristique : lieu de rencontre entre lexique et images du patrimoine culturel. vol. 2. Florence : FUP. p. VII-XVI.

(2012). «Lady Mary Wortley Montagu's Letters in France. Between Ideological Turn and Women's Writing ». In : PICKFORD, Susan ; MARTIN, Alison (éds.). Travel narratives in Translation, 1750-1830 : nationalism, ideology, gender. New York : Routledge. p. 157-180.

(2006). «Les Lettres de Lady Montague : réception en France d'une écriture féminine ». Publif@rum, n³. http://farum.it/publifarumv/n/03/pdf/Raus.pdf.

. (2003a). « Dinâmica da relação 'turcos-sultão' nos séculos XVII-XVIII e efeitos de sentido: pode-se falar de acontecimento semântico ? ». Trad. du français par André Giraud et Mariângela Joanilho. Línguas e instrumentos linguísticos, n. 9/10, p. 9-45.

. (2003b) «L'évolution de la locution 'à la turque'. Repenser l'événement sémantique », Langage \& Société, n 105, p. 39-68.

(2001a). «Pour une approche interdisciplinaire du stéréotype : le cas du topos d'Ulysse au XVIème siècle ». In : AA.VV., Langage et signification. Le Stéréotype: usages, formes et stratégies, Actes du XXIe Colloque d'Albi, 10-13 juillet 2000, SaintChamas, M.L.M.S. Éditeur, 2001. pp. 95-106.

(2001b). «La prise de parole du Turc dans la littérature de voyage française aux XVe-XVIe siècles : du silence fondateur à la suppression des stratégies de silenciement ». In : MARGARITO, Mariagrazia ; GALAZZI, Enrica ; POLITI, Monique Lebhar. Oralité dans la parole et dans l'écriture. Turin : Edizioni Cortina. p. 199-214. 
(2000a). «Stratégies discursives et épistolaires : les lettres de Milady Montague et de l'Abbé Sevin ». In: GIANOLIO, Valeria (éd.). Epistolari e conversari. Arti pratiche del dire. Turin : Tirrenia. p. 55.

. (2000b). Semantica ed analisi del discorso : il lemma Turc dal XVI alla prima metà del XIX secolo. Thèse de $3^{\text {ème }}$ cycle. Université de Trieste. https://www.openstarts.units.it/handle/10077/11594.

SIBLOT, Paul (1997). « De la prototypicalité lexicale à la stéréotypie discursive. La casbah des textes français ». In : PLANTIN, Christian (dir.). Lieux communs, topoï, stéréotypes, clichés. Paris : Éditions Kimé. p. 342-354.

Société de gens des Lettres et des savants (1811-1849). Biographie universelle ancienne et moderne. Paris : Ed. Michaud.

VOLTAIRE. (1843). Oeuvres complètes de Voltaire. Paris : Didot frères. . (1821). Oeuvres complètes de Voltaire. Paris : Renouard.

\section{Fontes}

Caylus comte (de). (1802). Voyage de M de Caylus. Annexe aux Lettres de Constantinople de M L'Abbé Sevin... au Comte de Caylus ...contenant des détails curieux sur l'empire ottoman. Paris: Obré.

Choiseul-Gouffier; Marie-Gabriel-Florent-Auguste comte (de). (1842). Voyage pittoresque dans l'Empire ottoman. Paris : J.-P. Aillaud.

Charrière, Ernest. (1848). Négociations de la France dans le Levant. In : Documents inédits sur l'histoire de France. Paris : Imprimerie Nationale.

Cornille, Henry. (1833). Souvenirs d'Orient. Constantinople, Grèce, Jerusalem, Egypte, 1831-33. Paris : A. Ledoux.

Lucas, Paul. (1704). Voyage du Sieur Paul Lucas au Levant. Paris: G. Vandive.

. (1719). Troisième voyage du Sieur Paul Lucas fait en 1714 par ordre de Louis $\overline{X I V}$ dans la Turquie, l'Asie, la Syrie, la Palestine, Rouen, R. Machuel le Jeune.

Montague-Wortley, Lady Mary. (1763). Lettres de M. de Wortley Montague, écrites pendant ses voyages en Europe, en Asie \& en Afrique \& traduites de l'Anglois sur la seconde édition. Amsterdam : J.F. Boitte.

(1764a). Lettres de Milady Marie Wortley Montague, écrites pendant ses voyages en Europe, en Asie et en Afrique (...) où on trouve, entr'autres Relations intéressantes, des Anecdotes sur les mœurs et les Gouvernement des Turcs, puisées dans de sources inaccessibles jusqu'ici aux autres voyageurs. Rotterdam : Chez H. Beman. (1764b). Lettres de Milady Wortlay Montagute, écrites pendant ses voyages 
en diverses parties du monde, traduites de l'Anglois. Nouvelle édition beaucoup plus correcte que les Editions qui viennent de paroître. Londres ; Paris : Duchesne.

. (1768). Lettres de Milady Worthley Montague, écrites pendant ses voyages en diverses parties du Monde. Troisième partie pour servir de Supplément aux deux premières. On y a joint une Réponse à la Critique que le Journal Encyclopédique a faite des deux premières parties de ces Lettres par M. G. [Guys] de Marseille. Paris ; Londres : veuve Duchesne.

(1799). Letters of the Right Honorable Lady Mary Wortley Montague, Written during her Travels in Europe, Asia and Africa. Berlin : Mylius.

Pouqueville, F.- C.-H.-L. (1805). Voyage en Morée, à Constantinople, en Albanie et dans plusieurs autres parties de l'Empire ottoman. Paris : Gabon.

Sevin, L'Abbé (de). (1802). Lettres sur Constantinople de M. l'Abbé Sevin (...) le tout imprimé sur les Originaux inédits par l'Abbé Bourlet de Vauxcelles. Paris : Chez Obré et Buisson.

Tott, Baron François (de). (1785). Memoires du Baron de Tott sur les Turcs et les Tartares. Maestricht : J. Dufour.

Tournefort, Pitton (de). (1717). Relation d'un voyage du Levant fait par ordre du Roy, contenant l'histoire ancienne et moderne de plusieurs isles de l'Archipel, de Constantinople, des Cotes de la Mer Noire, de l'Armenie, de la Georgie, des Frontières de Persies et de l'Asie Mineur, avec les Plans des villes et des lieux considerables, le moeurs, le commerce et la religion des peuples qui les habitent. Paris: Imprimerie royale.

\footnotetext{
${ }^{\mathrm{i}}$ Em todas as citações, padronizamos a grafia. [Dans toutes les citations nous avons normalisé la graphie.] ii Remetemo-nos à noção de «discurso imagético » (RAUS, 2017, VII-X), para aprofundar a relação entre texto, discurso e imagem. Disponível em: http://www.fupress.com/catalogo/le-guide-touristique-lieu-derencontre-entre-lexique-et-images-du-patrimoine--vol--ii/3360. Acesso em 03 mar.2018. [Nous renvoyons à la notion de " discours imagé » (RAUS, 2017, VII-X), pour approfondir la relation entre texte, discours et image.]

iii A presença de um discurso autônomo tomado como legítimo também faz com que as "viagens", as "observações" e "peregrinações", que caracterizam os títulos dos relatos no século XVI, tornem-se cada vez mais "relações", "memórias", "letras" e "jornais" nos séculos seguintes. [La présence d'un discours autonome ressenti comme légitime fait aussi que les « voyages », les « observations » et « pérégrinations » caractérisant les titres des récits au XVIème siècle, deviennent de plus en plus des « relations », des « mémoires », des « lettres » et des « journaux » aux siècles suivants.]

iv Para uma excursão histórica sobre a noção de « configuração de encunciados », confira Charaudeau e Maingueneau (2002, p. 121). [Pour un excursus historique sur la notion de «configuration d'énoncés » nous renvoyons à Charaudeau et Maingueneau (2002, p. 121).]

v N.T.: O "on" refere-se ao "se", a saber, partícula que representa o índice de indeterminação do sujeito em língua portuguesa.

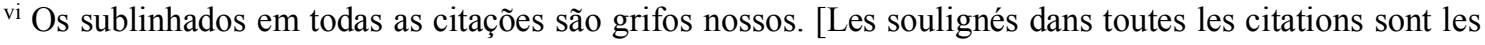
nôtres.]
} 
vii N.T.: Ao longo do texto, expressões como "blocage du sens", "bloquer le sens", "desbloquer le sens" serão traduzidas literalmente para a língua portuguesa ("bloqueio do sentido", "bloquear o sentido", "desbloquear o sentido").

viii N.T.: O termo "caravançarai" designava um tipo de estabelecimento de tipo hoteleiro (pousada ou estalagem).

${ }^{\text {ix }}$ N.T.: As palavras "Carbachara" e "Kiarvanserais" eram utilizadas no Oriente para designar o abrigo para os viajantes, hospedaria em que acolhiam as caravanas. (Fonte: http://www.larousse.fr/dictionnaires/francais/caravans\%C3\%A9rail/13112\#yTFurzAI6ZwWt85k.99.

Acesso em 26 fev. 2018).

${ }^{x}$ A descrição modalizada é o que permite aos viajantes contestar os « erros » dos viajantes anteriores que, em resumo, tinham trazido um olhar mais « transparente » em relação ao objeto de discurso. [La description modalisée est ce qui permet aux voyageurs de contester les «erreurs» des voyageurs précédents qui, somme toute, avaient porté un regard plus « transparent » par rapport à l'objet de discours.]

xi Além disso, Mondada esclarece, sobre os relatos de viagens na Itália, que (MONDADA, 2000, p. 168), "a relação de viagem inscreve os objetos de discursos no espaço do texto, distribuindo-lhes esquemas que exploram o percurso como princípio organizador", o que será em seguida retomado nos guias (viagens e turismo). [D'ailleurs, au sujet des récits de voyage en Italie, Mondada précise que (MONDADA, 2000, p. 168 ) « (1)a relation de voyage inscrit les objets de discours dans l'espace du texte, en les distribuant dans des schémas qui exploitent le parcours comme principe organisateur », ce qui ensuite sera repris dans les guides (de voyage et touristiques).]

xii Notemos que, no século XIX, graças principalmente à literatura do século anterior, a confusão entre o haremlik, o apartamento feminino ou o harém, e o palácio levará à utilização da palavra "Serralho" para se referir ao harém do palácio do Sultão. [Précisons qu'au XIXème siècle, grâce notamment à la littérature du siècle précédent, la confusion entre le haremlik, l'appartement des femmes ou harem, et le sérail aboutira à l'utilisation du mot « sérail » pour désigner le harem du sérail du sultan.]

xiii As categorias do «discurso autoritário » e do «discurso polêmico » serão igualmente retomadas e desenvolvidas por Eni Puccinelli Orlandi em seu livro Análise de discurso (1999/2015, p. 85), quando ela acrescentará também a categoria do « discurso lúdico ». [Les catégories de « discours autoritaire » et de « discours polémique » seront également reprises et développées par Eni Puccinelli Orlandi dans son livre Análise de discurso (1999/2015, p. 85), quand elle ajoutera également la catégorie du « discours ludique ».] xiv Nós transcrevemos o nome a partir da grafia francesa. [Nous transcrivons le nom d'après la graphie française.]

${ }^{x v}$ Entre os destinatários homens, citemos o Abade Conti e Alexander Pope. [Parmi les destinataires hommes citons l'Abbé Conti et Alexander Pope.]

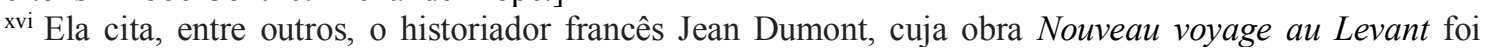
traduzida para o inglês em 1694. [Elle cite, entre autres, l'historien français Jean Dumont, dont le Nouveau voyage au Levant avait été traduit en anglais en 1694.]

xvii As citações das «Cartas» são tiradas da tradução de 1764 (MONTAGUE-WORTLEY, 1764a), a saber, a reimpressão da publicação feita em Roterdã, em 1763, tradução que permanece fiel ao original. Por outro lado, em relação às traduções seguintes, nós reencaminhamos ao parágrafo 2.3.2. [Les citations des Lettres sont tirées de la traduction de 1764 (MONTAGUE-WORTLEY, 1764a), à savoir la réimpression de la publication faite à Rotterdam en 1763, traduction qui reste très fidèle à l'original. Par contre, par rapport aux traductions suivantes, nous renvoyons au paragraphe 2.3.2.]

xviii A sultana indicava normalmente a validé, isto é, a mãe do sultão. [La sultane indiquait normalement la validé, c'est-à-dire la mère du sultan.]

${ }^{\text {xix }} \mathrm{Na}$ verdade, vale para as mulheres turcas o discurso que Orlandi faz para o índio do Brasil de quem outros falam, mas que nunca fala. [En effet, il valait pour les femmes turques le discours que Orlandi fait pour l'Indien du Brésil dont les autres parlent mais qui ne parle jamais.] 


\begin{abstract}
${ }^{x x}$ Em 1803, o editor inglês James Dallaway denunciava as seis cartas adicionais como falsas em suas Works of the Right honorable Lady Mary Worthley Montagu including the correspondance, poems and essays published by permission from her genuine papers (London: Richard Philipps). Em sua edição de Cartas publicadas em 1965 (The complete letters of Lady Mary Wortley Montagu, Oxford: Clarendon), Robert Halsband denunciará como "espúrias" cinco das seis cartas adicionais, considerando que apenas a carta endereçada ao Abade Conti, em fevereiro 1718, cujo original em francês tinha sido encontrado pela editora, era verdadeira. [En 1803, l'éditeur anglais James Dallaway dénonçait les six lettres supplémentaires comme fausses dans ses Works of the Right honorable Lady Mary Worthley Montagu including the correspondance, poems and essays published by permission from her genuine papers (London : Richard Philipps). Dans son édition des Lettres parue en 1965 (The complete letters of Lady Mary Wortley Montagu, Oxford : Clarendon), Robert Halsband dénoncera comme « spurious » cinq des six lettres supplémentaires, en considérant que seulement la lettre adressée à l'Abbé Conti en février 1718, dont l'original en français avait été retrouvé par l'éditeur, était vraie.]

xxi Isso não é surpreendente se este é justamente o século em que aparecem viajantes “pitorescos”. [Ce n'est donc pas étonnant si celui-ci est justement le siècle où paraissent les voyages « pittoresques ».]
\end{abstract}

Artigo recebido em: novembro de 2017.

Aprovado e revisado em: março de 2018.

Publicado em: maio de 2018.

\title{
Para citar este texto:
}

RAUS, Rachelle. Construção de um objeto de discurso e memória discursiva: o exemplo de Constantinopla nos relatos de viagem do século XVIII [Construction d'un objet de discours et mémoire discursive: l'exemple de Constantinople dans les récits de voyage au XVIIlème siècle, versão bilíngue pt-fr]. Entremeios [Revista de Estudos do Discurso, ISSN 2179-3514, on-line, www.entremeios.inf.br], Seção Estudos, Programa de PósGraduação em Ciências da Linguagem (PPGCL), Universidade do Vale do Sapucaí (UNIVÁS), Pouso Alegre (MG), vol. 16, p. 43-78, jan. - jun. 2018. DOI: $\underline{\text { ttp://dx.doi.org/10.20337/ISSN2179-3514revistaENTREMEIOSvol16pagina43a78 }}$ 